\title{
POSTNATAL DEVELOPMENT OF DOPAMINERGIC NEURONS IN THE RABBIT RETINA ${ }^{1}$
}

\author{
DOMINIC MAN-KIT LAM, \\ ${ }^{*}$ Cullen Eye Institute and Program in Neuroscience, Baylor College of Medicine, Houston, Texas 77030 and $\ddagger$ Department of Biochemistry, \\ Chinese University of Hong Kong, Shatin, Hong Kong
}

\begin{abstract}
The emergence and maturation of dopaminergic neurons during postnatal development of the rabbit retina have been followed using high affinity uptake, content, synthesis, storage, metabolism, and release of dopamine as transmitter-specific physiological probes. Autoradiographic and histochemical studies have shown that dopamine-containing neurons in the rabbit retina belong to a class of amacrine cells whose processes ramify mainly in the most distal region of the inner plexiform layer. These neurons contain high concentrations of dopamine, take up dopamine by a high affinity mechanism, and release the accumulated dopamine by a $\mathrm{Ca}^{2+}$-dependent mechanism upon depolarization of the retina with high extracellular $\mathrm{K}^{+}$. In addition, the rabbit retina contains significant activities of tyrosine 3-hydroxylase (TH, EC 1.14.16.2) and monoamine oxidase (EC 1.4.3.4), the rate-limiting enzymes for the biosynthesis and degradation of dopamine, respectively.

In the present study, we show that certain neurons in the newborn retina already possess a specific mechanism for dopamine uptake. The position, density, morphology, and ramification of these cells in the developing retina strongly suggest that they will become dopaminergic neurons in the adult retina. In addition, the ability of the newborn retina to release the accumulated dopamine upon $\mathrm{Ca}^{2+}$-dependent $\mathrm{K}^{+}$stimulation is qualitatively similar to that of the adult retina. These putative dopaminergic neurons are, however, probably immature at birth because newborn retinas contain very low levels of TH activities and endogenous dopamine. The activities of retinal TH are extremely low between days 0 and 6 after birth, increasing slowly to $30 \%$ of the adult level by day 18 . There is then a drastic rise in TH activity, reaching the adult level by day 25 . The concentration of dopamine in the developing retinas follows closely the increase in TH activity, rising in the same biphasic pattern and reaching the adult level at about 25 days after birth.

Taken together, our results indicate that, in the rabbit retina, the commitment for certain neurons to be dopaminergic is made prenatally. This is similar to our earlier findings that putative GABAergic and glycinergic neurons also are determined prenatally. The patterns of maturation for dopaminergic neurons are, however, very different from those for GABAergic and glycinergic neurons. Unlike GABAergic and glycinergic neurons which are mature around or shortly after the time the animals first open their eyes (10 to 12 days after birth), on the basis of 'TH activities and dopamine contents, the dopaminergic neurons cannot be considered mature until about 25 days after birth.
\end{abstract}

A characteristic feature during the development of a nervous system is the emergence and maturation of specific neurotransmitter systems in different neurons. In the vertebrate retina, there is considerable evidence

\footnotetext{
${ }^{1}$ We wish to thank Dr. Jeanne Frederick, Ms. Patricia Glazebrook, and Ms. Patricia Cloud for their assistance in preparing the manuscript. This work was supported by research grants from the United States National Institutes of Health (EY02608) and the Retina Research Foundation (Houston). Dominic M. K. Lam is the recipient of a Research to Prevent Blindness-Olga Weiss Scholar Award from Research to Prevent Blindness, Inc., New York and a Research Career Development award from the United States National Eye Institute. Part of this work was done when Dominic M. K. Lam was a visiting
}

for $\gamma$-aminobutyric acid (GABA), glycine, and dopamine as neurotransmitters (Ames and Pollen, 1969; Brandon et al., 1980; Dowling and Ehinger, 1978; Graham, 1974; Kong et al., 1980; Lam, 1976; Lam et al., 1979). The neurons which use these substances as transmitters have been shown to contain high concentrations of these substances and their synthetic enzymes, to possess high affinity uptake mechanisms for these transmitters, and

\footnotetext{
research professor in the Department of Biochemistry, Chinese University of Hong Kong.

${ }^{2}$ Present address: Department of Physiology, Oxford University, St. Cross Road, OX1 3JA, England.
} 
to release them in response to appropriate depolarizing stimuli. We have recently used these specific properties as physiological probes to follow the development of the GABAergic, glycinergic, and dopaminergic systems in identified neurons during differentiation and maturation of Xenopus and rabbit retinas.

This is the third paper in our series of studies on the development of neurotransmitter systems in the rabbit retina. In this paper, we examine the emergence and maturation of dopaminergic neurons and compare these results to the developmental patterns reported previously for GABAergic and glycinergic neurons (Kong et al., 1980; Lam et al., 1980).

\section{Materials and Methods}

Injections and incubations. The procedures used for the uptake and release experiments have been described in detail elsewhere (Kong et al., 1980; Lam et al., 1980). Eighty New England white (albino) rabbits aged 0 to 60 days and 10 adult rabbits were used for this study. For the first several weeks after birth, each litter of pups was raised with its mother in a large cage containing a wooden nesting box. They were kept under uniform conditions and fed a standard Purina Laboratory Rabbit Chow with drinking water ad libitum. The animal house was kept at a normal 12-hr dark-light cycle. The eyes were in a lightadapted state during the experiments. The uptake and release of dopamine were studied using $\left[{ }^{3} \mathrm{H}\right]$ dopamine (3,4-[ethyl-1 - $\left.{ }^{3} \mathrm{H}(\mathrm{N})\right]$ dihydroxyphenylethylamine; specific activity, $15.4 \mathrm{Ci} / \mathrm{mmol}$; New England Nuclear Corp., Boston, MA). In these experiments, a rabbit was anesthetized with ether under room light and $50 \mu \mathrm{l}$ of isotonic saline solution containing $50 \mu \mathrm{Ci}$ of $\left[{ }^{3} \mathrm{H}\right]$ dopamine was injected into the vitreous of one eye through the cornealscleral junction. The injection site could be visualized by observing the tip of the hypodermic needle through the lens. Since the eyes of rabbits aged 0 to 10 days after birth are still closed, the eyclids first were slit open with a razor blade before the injection. Ninety minutes after the injection, the animal was anesthetized with ether and decapitated. The injected eye was enucleated; the retina then was isolated and placed on a Petri dish containing Ames' bicarbonate-buffered Ringer's solution (pH 7.4) (Ames and Pollen, 1969; Webster and Ames, 1969) oxygenated with $5 \% \mathrm{CO}_{2}$ and $95 \% \mathrm{O}_{2}$. After removal of all of the vitreous and the most peripheral regions of the retina, the rest of the retina was cut into five approximately equal pie-shaped pieces and each was placed in a separate Petri dish containing $4 \mathrm{ml}$ of Ringer's solution.

Autoradiography. After washing for 3 min in Ringer's solution, one piece of retina from the injected eye was transferred to a fixative containing $2 \%$ glutaraldehyde and $1 \%$ paraformaldehyde in $100 \mathrm{~mm}$ sodium phosphate buffer ( $\mathrm{pH} 7.2$ ). The retina was fixed for $1 \mathrm{hr}$ at room temperature and overnight at $4{ }^{\circ} \mathrm{C}$, post-fixed with $1 \%$ $\mathrm{OsO}_{4}$, dehydrated with ethanol, and embedded in Epon/ Araldite mixture. Sections, 1 to $2 \mu \mathrm{m}$ thick, were cut and placed on pre-cleaned glass microscopic slides. Slides were dipped in the dark with Kodak NTB2 liquid emulsion (diluted $1: 1$ with water) at $40^{\circ} \mathrm{C}$. After 10 to 50 days of exposure at $4^{\circ} \mathrm{C}$ in the dark, the slides were developed for $2 \mathrm{~min}$ at $15^{\circ} \mathrm{C}$ in Kodak Dektol (diluted 1:1 with water) fixed with Kodak fixer at $15^{\circ} \mathrm{C}$ for $15 \mathrm{~min}$. The autoradiographs then were washed with three changes of distilled water, stained with $1 \%$ toluidine blue, and examined by light microscopy to determine the presence and localization of $\left[{ }^{3} \mathrm{H}\right]$ dopamine uptake.

Release experiments. Four pieces of retina from the injected eye each were incubated at room temperature in a Petri dish containing $5 \mathrm{ml}$ of Ringer's solution for 1 hr. The medium was changed every $5 \mathrm{~min}$. In order to enhance effective exchange between the extracellular fluid and the Ringer's solution, the Petri dishes were placed on a shaker set at a moderate speed. After $1 \mathrm{hr}$ of washing, the spontaneous efflux of radioactivity from each piece of retina usually reached a steady basal level. Each piece of retina then was transferred to a graduated conical tube containing either $2 \mathrm{ml}$ of normal Ringer's solution or an isotonic Ringer's solution in which $56 \mathrm{~mm}$ $\mathrm{NaCl}$ had been replaced by $56 \mathrm{~mm} \mathrm{KCl}\left(\mathrm{K}^{+}\right.$rich) to examine the presence of $\mathrm{K}^{+}$-stimulated $\left[{ }^{3} \mathrm{H}\right]$ dopamine release. The medium in each tube was changed every 3 min. One milliliter of each eluate was mixed thoroughly with $9 \mathrm{ml}$ of a scintillant mixture $(667 \mathrm{ml}$ of toluene, 333 ml of Triton X-100, $5.5 \mathrm{gm}$ of PPO (2,5-diphenyloxazole), and $0.1 \mathrm{gm}$ of POPOP (1,4-bis-2-(5-phenyloxazolyl) benzene)), and the radioactivity was measured by a liquid scintillation counter (Beckman, model LS-330). Ten microliters of each eluate was used to determine, by high voltage paper electrophoresis, the percentage of total radioactivity remaining as $\left[{ }^{3} \mathrm{H}\right]$ dopamine (Hildebrand et al., 1971). The $\mathrm{Ca}^{2+}$ dependence of this release was studied by adding $\mathrm{CoCl}_{2}$ to either normal or $\mathrm{K}^{+}$-rich Ringer's solution at a final concentration of $10 \mathrm{~mm}$ during the appropriate intervals. The $\mathrm{K}^{+}$-stimulated $\mathrm{Ca}^{2+}$-dependent release of $\left[{ }^{3} \mathrm{H}\right]$ dopamine from the retina was expressed (in percent) as the ratio of total disintegrations per min of $\left[{ }^{3} \mathrm{H}\right]$ dopamine released into the medium due to $\mathrm{Co}^{2+}$-inhibited $\mathrm{K}^{+}$stimulation over the total disintegrations per min of $\left[{ }^{3} \mathrm{H}\right]$ dopamine remaining in the retina at the time of the $\mathrm{K}^{+}$-induced release. After each release experiment, the retina was homogenized with a glass homogenizer (from Kontes Glass Co., Vineland, NJ) in 1 $\mathrm{ml}$ of $40 \%$ trichloroacetic acid. Twenty microliters of the supernatant was used to determine the percentage of the total radioactivity in the retina remaining as $\left[{ }^{3} \mathrm{H}\right]$ dopamine using high voltage paper electrophoresis (Hildebrand et al., 1971).

In order to protect the $\left[{ }^{3} \mathrm{H}\right]$ dopamine from degradation, sodium ascorbate (from Merck) and pargyline hydrochloride (from Regis Chemical Co.) were added to the Ringer's solution at final concentrations of $1 \mathrm{~mm}$ and 15 $\mu \mathrm{M}$, respectively.

Assay of tyrosine hydroxylase. Tyrosine hydroxylase (EC 1.14.16.2) activities were measured using the methods described by Nagatsu et al. (1964) and Coyle (1972) with some modifications. Retinas were homogenized in $5 \mathrm{vol}(\mathrm{w} / \mathrm{v})$ of $50 \mathrm{~mm}$ potassium phosphate buffer $(\mathrm{pH} 6)$ containing $0.2 \%$ Triton $\mathrm{X}-100$. The homogenates were centrifuged with an Eppendorf Microfuge model 5412 in a cold room at $10,000 \times g$ for $10 \mathrm{~min}$. The supernatant was decanted for assay. Fifty microliters of the supernatant of the retinal homogenates was added to each $15-\mathrm{ml}$ glass centrifuge tube containing a reaction mixture of 10 
$\mu \mathrm{l}$ of $1 \mathrm{M}$ potassium phosphate buffer (pH 6), 1,100 units of catalase (EC 1.11.1.6; 13,800 units/mg; Sigma) in 10 $\mu \mathrm{l}$ of glass-distilled water, $20 \mu \mathrm{l}$ of $50 \mathrm{units} / \mathrm{ml}$ of dihydropteridine reductase (EC 1.6.99.7; Sigma), $5 \mu \mathrm{l}$ of 0.01 M reduced nicotinamide-adenine dinucleotide phosphate (Sigma), $10 \mu \mathrm{l}$ of $6.4 \mathrm{~mm} 2$-amino-4-hydroxy-6,7-dimethyltetrahydropteridine (Sigma) freshly prepared in ice cold $0.005 \mathrm{M} \mathrm{HCl}, 5 \mu \mathrm{l}$ of $63 \mathrm{~mm}$ freshly prepared ferrous ammonium sulfate solution. Blanks were prepared by replacing the supcrnatant with distilled water. The reaction was initiated by the addition of $10 \mu \mathrm{l}$ of 2.26 mM L- $\left[{ }^{14} \mathrm{C}\right]$ tyrosine (uniformly labeled; specific activity, $22.1 \mathrm{mCi} / \mathrm{mmol}$; New England Nuclear Corp., Boston, $\mathrm{MA}$ ) and was incubated for $30 \mathrm{~min}$ at $37^{\circ} \mathrm{C}$ in room air. The reaction was terminated by the addition of $6 \mathrm{ml}$ of $0.4 \mathrm{M}$ perchloric acid containing $6 \mu \mathrm{g}$ of carrier of $\mathrm{L}$-dopa (Sigma). The perchlorate-inactivated incubated mixture was centrifuged at $1,000 \times g$ for $10 \mathrm{~min}$; the supernatant was added to a $20-\mathrm{ml}$ Erlenmyer flask containing $400 \mathrm{mg}$ of acid-washed alumina (Merck) pre-activated at $110^{\circ} \mathrm{C}$ for $1 \mathrm{hr}, 5 \mathrm{ml}$ of $2 \%$ EDTA (ethylenediaminetetra-acetate, $\mathrm{w} / \mathrm{v}), 1.5 \mathrm{ml}$ of $0.35 \mathrm{M}$ potassium phosphate, and $30 \mathrm{mg}$ of sodium disulfite. The mixture was stirred and titrated to $\mathrm{pH} 8.6$ with $1 \mathrm{~m} \mathrm{NaOII}$. After shaking for $5 \mathrm{~min}$, the absorbent then was allowed to settle and the liquid was decanted. Then the alumina was resuspended in $4 \mathrm{ml}$ of $100 \mathrm{~mm}$ potassium phosphate buffer ( $\mathrm{pH} \mathrm{8.6)}$ and charged over a $0.6 \times 10 \mathrm{~cm}$ column. The columns were washed with another $16 \mathrm{ml}$ of the buffer. The $\left[{ }^{14} \mathrm{C}\right]$ dopa so formed was eluted with $3 \mathrm{ml}$ of $0.3 \mathrm{M}$ acetic acid and the radioactivily was measured by liquid scintillation counting. The results were corrected for recovery of dopa, which was consistently found to be 69 to $71 \%$. For kinetic studies, substrate concentrations ranging from $0.2 \mathrm{~mm}$ to $12.5 \mu \mathrm{M}$ were used.

Determination of endogenous dopamine content. The endogenous levels of dopamine were determined by means of a sensitive, radioenzymatic assay described by Coyle and Hendry (1973). Catecholamines were converted into their corresponding 3-O-methylated derivatives in the presence of catechol $O$-methyltransferase and ${ }^{[} \mathrm{H} H \mid$ methyl $S$-adenosylmethionine. The tritiated derivatives were separated by selective solvent extraction. Rabbits were sacrificed by cervical dislocation, and the retinas were isolated in $0.25 \mathrm{M}$ ice cold sucrose solution, then blotted, and weighed. The tissue was frozen quickly in liquid nitrogen within $2 \mathrm{~min}$ and stored at $-80^{\circ} \mathrm{C}$. The frozen retinal tissue was homogenized in $20 \mathrm{vol}(\mathrm{w} / \mathrm{v})$ of $0.1 \mathrm{M}$ perchloric acid with a glass homogenizer. The homogenates were centrifuged at $15,000 \times g$ for $20 \mathrm{~min}$. The supernatant was decanted for assay.

Three hundred microliters of the supernatant was placed in $15-\mathrm{ml}$ centrifuge tubes. Standards consisting of $5 \mathrm{ng}$ of dopamine $\mathrm{HCl}$ (from Sigma) in $10 \mu \mathrm{l}$ of $0.1 \mathrm{M}$ perchloric acid were added to $300 \mu \mathrm{l}$ of the supernatant for each assay. The reaction was initiated with the addition of $100 \mu \mathrm{l}$ of a mixture containing $500 \mu \mathrm{g}$ of DLdithiothreitol (Sigma), $0.5 \mu \mathrm{mol}$ of $\mathrm{MgCl}_{2}, 140 \mu \mathrm{mol}$ of Tris-HCl buffer ( $\mathrm{pH} 9.6), 25 \mu \mathrm{l}$ of 80 units/ml catechol $O$ methyltransferase (EC 2.1.1.1; from Sigma), $2.5 \mu \mathrm{Ci}$ of $S$ [ methyl- ${ }^{3} \mathrm{H}$ ] adenosyl-L-methionine (specific activity, 4.52 $\mathrm{Ci} / \mathrm{mmol}$; New England Nuclear Corp., Boston, MA) The reaction mixture was incubated for $60 \mathrm{~min}$ at $35^{\circ} \mathrm{C}$ in a Dubnoff metabolic shaker. The reaction was stopped by the addition of $150 \mu \mathrm{l}$ of $1 \mathrm{~m}$ borate buffer ( $\mathrm{pH} 11$ ).

After the addition of nonradioactive carriers $(7 \mu \mathrm{g}$ of methoxytyramine $\cdot \mathrm{HCl}, 3 \mu \mathrm{g}$ of DL-normetanephrine. $\mathrm{HCl}$, and $3 \mu \mathrm{g}$ of DL-metanephrine $\cdot \mathrm{HCl}$; all from Sigma), the $O$-methylated products were extracted into watersaturated ethyl acetate:methanol $(10: 1, \mathrm{v} / \mathrm{v})$ by mixing with a whirlmixer for $30 \mathrm{sec}$. The phases were separated by low speed centrifugation. The organic phase was aspirated and discarded. The acid phase was washed with $8 \mathrm{ml}$ of water-saturated ethyl acetate, and the organic phase was discarded.

The centrifuge tubes then were transferred to an ice bath and $0.5 \mathrm{ml}$ of $0.5 \mathrm{M}$ sodium phosphate buffer $(\mathrm{pH}$ 7.5) was added to each tube. The dopamine- and norepinephrine-derived products were separated by cleaving the side chains at the $\beta$-hydroxy group. Fifty microliters of $3 \%(\mathrm{w} / \mathrm{v})$ sodium metaperiodate (Merck) was added, followed by $50 \mu \mathrm{l}$ of $10 \%(\mathrm{v} / \mathrm{v})$ glycerol after $2 \mathrm{~min}$. [methyl $-{ }^{3} \mathrm{H}$ ]Vanillin, the cleavage product of norepinephrine, was extracted into $10 \mathrm{ml}$ of toluene, and the organic phase was aspirated and discarded. The aqueous phase was used for dopamine determination. To each tube, 0.5 $\mathrm{ml}$ of $1 \mathrm{M}$ borate buffer $(\mathrm{pH} \mathrm{11)}$ and $8 \mathrm{ml}$ of toluene: isoamyl alcohol $(3: 2, \mathrm{v} / \mathrm{v})$ were added and the [methyl${ }^{3} \mathrm{H}$ ]methoxytyramine was extracted into the organic phase. Four milliliters of the organic phase was counted with $10 \mathrm{ml}$ of scintillant mixture. When corrected for extraction procedures, over $80 \%$ of the catecholamines were converted to their ${ }^{3} \mathrm{II} O$-methylated derivatives in the absence of tissue. Tissue extracts reduced the recovery of the labeled products; the recovery factor for a 20 fold dilution remained consistently at about $60 \pm 6 \%$.

Assay of monoamine oxidase. The assay method of monoamine oxidase (MAO, EC 1.4.3.4) was modified from that described by Berrentini et al. (1978). Rabbits were killed by cervical dislocation and the retinas were isolated in $0.25 \mathrm{~m}$ ice cold sucrose solution, blotted, and weighed for storage at $-80^{\circ} \mathrm{C}$ until use. The retinal tissues were homogenized in $10 \mathrm{vol}(\mathrm{w} / \mathrm{v})$ of $50 \mathrm{~mm}$ sodium phosphate buffer ( $\mathrm{pH} 7.4)$ with a glass homogenizer and centrifuged at $1,000 \times g$ for $2 \mathrm{~min}$, and each supernatant was removed for enzyme assay. One hundred microliters of the supernatant was added to each $15 \mathrm{ml}$ of sodium phosphate ( $\mathrm{pH}$ 7.4). The reaction was initiated by the addition of $50 \mu \mathrm{l}$ of $3 \mathrm{~mm} 3,4-\left[e t h y l-2-{ }^{3} \mathrm{H}(\mathrm{N})\right]-$ dihydroxyphenylethylamine (specific activity, $11 \mathrm{mCi}$ / mmol; New England Nuclear Corp., Boston, MA). The reaction mixture was incubated at $37^{\circ} \mathrm{C}$ for $30 \mathrm{~min}$ in a Dubnoff metabolic shaker. For the control experiment, $100 \mu \mathrm{l}$ of $0.5 \mathrm{M}$ sodium phosphate buffer ( $\mathrm{pH} 7.4$ ) was added instead of the retinal extracts. The reaction was stopped by adding $1 \mathrm{ml}$ of $2 \mathrm{M} \mathrm{HCl}$. The reaction product, 3,4-dihydroxyphenylacetic acid was extracted into $6 \mathrm{ml}$ of toluene:tetrahydrofuran $(2: 1, \mathrm{v} / \mathrm{v})$ by mixing in a Vortex mixer for $15 \mathrm{sec}$. Three milliliters of the organic phase was counted for radioactivity with the addition of $10 \mathrm{ml}$ of scintillant mixture. With this method of solvent extraction, over $99.5 \%$ of the substrate remained in the aqueous phase. For kinetic studies, substrate concentrations ranging from 0.5 to $0.05 \mathrm{~mm}$ were used. 
Pharmacological study of monoamine oxidase. The inhibitory effects of an irreversible MAO-A selective inhibitor, clorgyline (May and Baker Ltd., Essex, England) (Johnston, 1968), and irreversible MAO-B selective inhibitor, deprenyl (from Dr. J. Knoll, Semmelweis University of Medicine, Budapest, Hungary) (Knoll and Magyar, 1972), on retinal MAO activities were studied with concentrations ranging from $10^{-3}$ to $10^{-13} \mathrm{M}$. In each set of experiments, appropriate concentrations of the inhibitors were preincubated with the supernatant of retinal homogenate for $15 \mathrm{~min}$ at $37^{\circ} \mathrm{C}$ before the addition of the substrates. The same protocol described earlier was applied, using $0.6 \mathrm{~mm}\left[{ }^{3} \mathrm{H}\right]$ dopamine $\cdot \mathrm{HCl}$ (specific activity, $11 \mathrm{mCi} / \mathrm{mol}$; New England Nuclear Corp., Boston, MA) as the substrate.

In another series of experiments, tryptamine was used as the substrate (Wurtman and Axelrod, 1963). Retinas were homogenized with 10 times the wet weight of $50 \mathrm{~mm}$ ice cold sodium phosphate buffer ( $\mathrm{pH}$ 7.4). The homogenate was centrifuged at $1,000 \times g$ for $2 \mathrm{~min}$. One hundred microliters of the supernatant was added to $100 \mu \mathrm{l}$ of 0.5 M sodium phosphate buffer ( $\mathrm{pH}$ 7.4). The reaction was initiated by adding $100 \mu \mathrm{l}$ of $0.52 \mathrm{~mm}$ [side chain-2- ${ }^{14} \mathrm{C}$ ]tryptamine bisuccinate (specific activity, $1.92 \mathrm{Ci} / \mathrm{mmol}$; New England Nuclear Corp., Boston, MA). The reaction mixture was incubated at $37^{\circ} \mathrm{C}$ for $30 \mathrm{~min}$ and was terminated by the addition of $0.2 \mathrm{ml}$ of $2 \mathrm{M} \mathrm{HCl}$. The reaction product was extracted with $6 \mathrm{ml}$ of toluene. For control experiments, $100 \mu \mathrm{l}$ of $0.5 \mathrm{M}$ sodium phosphate buffer ( $\mathrm{pH}$ 7.4) was used instead of the supernatant. The tube then was mixed in a Vortex mixer for 15 sec and 3 $\mathrm{ml}$ of the organic phase was aspirated for the measurement of radioactivity.

Monoamine oxidase in the rabbit retina was characterized further by using benzylamine as a substrate. Benzylamine is known as a MAO-B-specific substrate. The assay procedure was modified from that described by Tabor et al. (1954) and McEwen and Cohen (1963). Retinas were homogenized in 10 times the wet weight of $50 \mathrm{~mm}$ sodium phosphate buffer ( $\mathrm{pH} 7.2)$ and then centrifuged at $1,000 \times g$ for $2 \mathrm{~min}$. Six hundred microliters of the supernatant was added to $0.75 \mathrm{ml}$ of $0.2 \mathrm{M}$ sodium phosphate buffer ( $\mathrm{pH} 7.2$ ) and the reaction was initiated by the addition of $0.15 \mathrm{ml}$ of $8 \mathrm{~mm}$ benzylamine (BDH). The control experiments were identical to the test except that the substrate was not added until the end of the incubation. The incubation mixture was shaken at $37^{\circ} \mathrm{C}$ for $2 \mathrm{hr}$. The reaction was stopped by the addition of 0.15 $\mathrm{ml}$ of $60 \%$ perchloric acid. The reaction product is benzaldehyde which was extracted with $1.5 \mathrm{ml}$ of cyclohexane by mixing in a Vortex mixer for $10 \mathrm{sec}$. The mixing was repeated for $10 \mathrm{sec}$ after standing at room temperature for $15 \mathrm{~min}$. The phases were separated by centrifugation at $2,000 \times g$ for $10 \mathrm{~min}$. The organic phase was read against the blank for absorbance at $242 \mathrm{~nm}$ using a Hitachi UV-VIS Spectrophotometer (model 139).

Identification of metabolites. High voltage paper electrophoresis was utilized for the separation and identification of metabolites in the retinas incubated with $\left[{ }^{3} \mathrm{H}\right]-$ dopamine and the eluates of the release experiments (Hildebrand et al., 1971). Whatman No. 3MM paper (52 $\times 20 \mathrm{~cm}$ ) was used and the separation was performed by high voltage electrophoresis (Shandon, model L24) at $6,000 \mathrm{~V}$ for $1 \mathrm{hr}$. The solvent system was a mixture of 1.4 $\mathrm{m}$ acetic acid and $0.47 \mathrm{~m}$ formic acid at $\mathrm{pH} 1.9$. Ten microliters of the eluate was spotted onto the paper after $10 \mu \mathrm{l}$ of the corresponding carrier solution was placed as a marker. The optimal concentration of dopamine used is $0.5 \mathrm{mg} / \mathrm{ml}$. After electrophoresis, the position of dopamine on the paper was identified by spraying the paper with ferricyanide/ethylenediamine solution $(0.1 \%$ $\mathrm{K}_{3} \mathrm{Fe}(\mathrm{CN})_{6}$ in $5 \%(\mathrm{v} / \mathrm{v})$ ethylenediamine). The paper then was dried for $5 \mathrm{~min}$ at $50^{\circ} \mathrm{C}$. The reaction products fluoresce upon ultraviolet illumination. The paper was cut into 1-cm squares and eluted with $2 \mathrm{ml}$ of water, and the radioactivity was measured.

Protein determination. Protein contents were determined by the method of Lowry et al. (1951), using bovine serum albumin as standard. Absorbance was measured with a Hitachi UV-VIS Spectrophotometer (model 139).

\section{Results}

Dopamine-accumulating neurons in the adult retina. After an intraocular injection of $\left[{ }^{3} \mathrm{H}\right]$ dopamine, the radioactivity is confined to the inner plexiform layer and to occasional somas in the vitreal side of the inner nuclear layer (Fig. 1). The density of $\left[{ }^{3} \mathrm{H}\right]$ dopamine-accumulating somas (between 0.4 and 1.2 somas/mm of linear retinal expanse) is much lower than the densities of GABA- and glycine-accumulating somas (49 and 70 , respectively; Kong et al., 1980; Lam et al., 1980) in the rabbit retina.

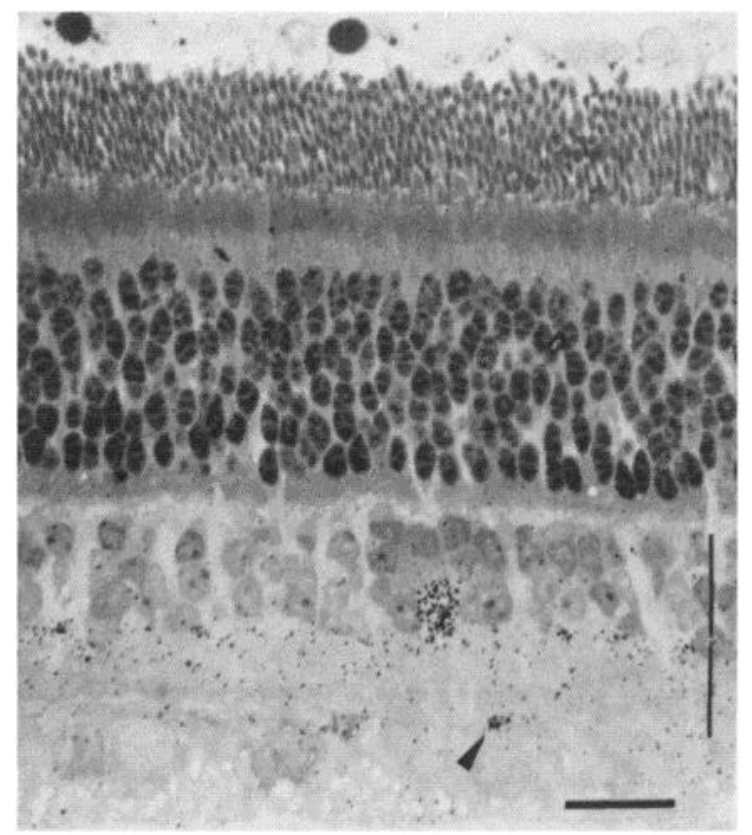

Figure 1. Light microscope autoradiograph of an adult rabbit retina $1 \mathrm{hr}$ after an intraocular injection of $50 \mu \mathrm{Ci}$ of $\left[{ }^{3} \mathrm{H}\right]$ dopamine in vivo. A labeled soma is located at the vitreal side of the inner nuclear layer (upper vertical bar). This neuron is most likely an amacrine cell. Within the inner plexiform layer (lower vertical bar), the label is concentrated in a band adjacent to the inner nuclear layer although there also are labeled punctate terminals (arrowhead) deeper in the inner plexiform layer. Scale bar, $20 \mu \mathrm{m}$. 


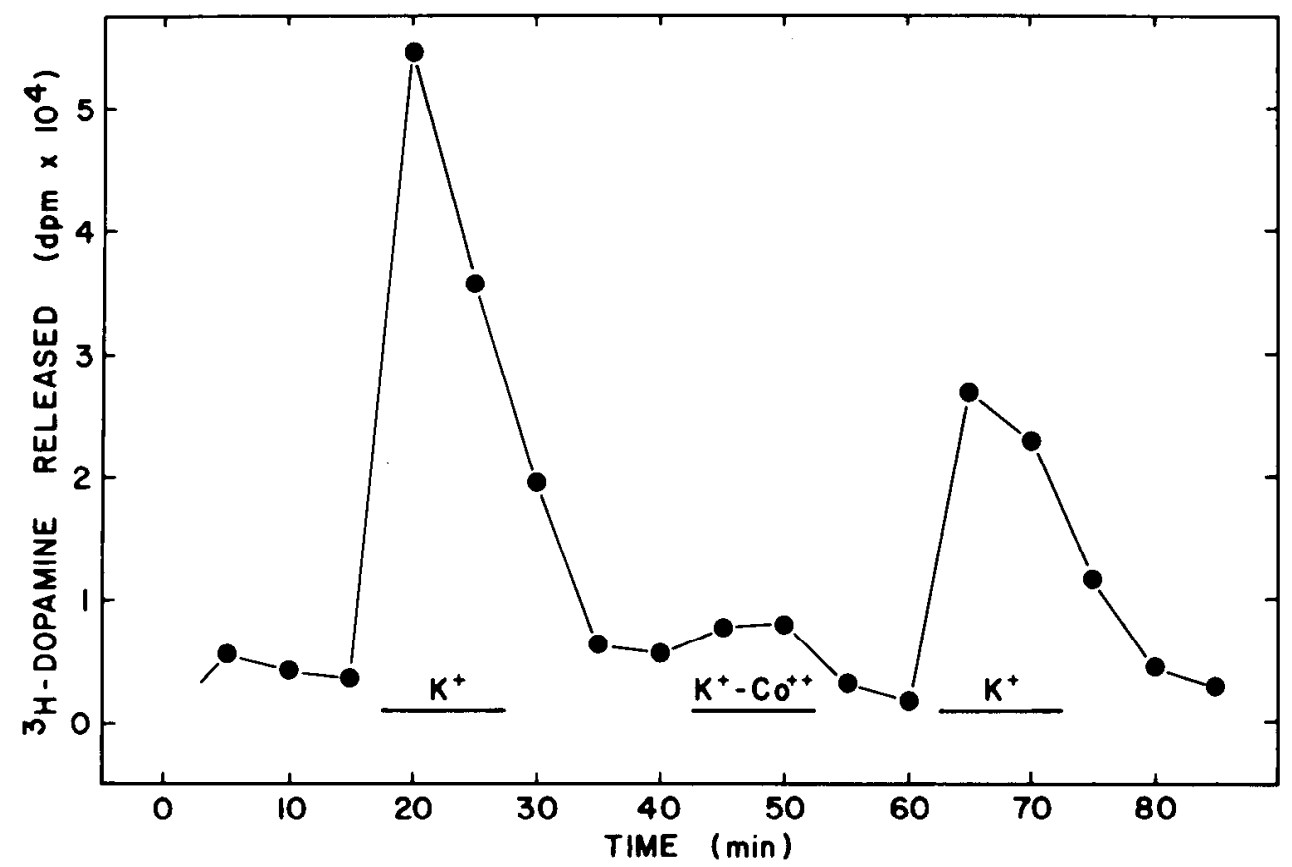

Figure 2. $\mathrm{K}^{+}$-stimulated release of $\left[{ }^{3} \mathrm{H}\right]$ dopamine from an adult rabbit retina. This figure also shows the effect of $10 \mathrm{mM} \mathrm{Co}{ }^{2+}$ on $\mathrm{K}^{+}$-stimulated dopamine release $\left(\mathrm{K}^{+}-\mathrm{Co}^{++}\right)$. Similar results were obtained in five other experiments.

Analyses by high voltage paper electrophoresis of the radioactive products in the retina $1 \mathrm{hr}$ after the injection showed that $89.9 \pm 2.5 \%$ of the radioactivity was still associated with $\left[{ }^{3} \mathrm{H}\right]$ dopamine. The position and lamination pattern of the dopamine-accumulating cells indicate that these probably belong to a type of amacrine cells. These cells ramify mainly in a sharp band adjacent to the inner nuclear layer with occasional punctate terminals deeper in the inner plexiform layer. The number and morphology of these cells in the rabbit retina are very similar to the dopamine-containing cells, as revealed previously by histofluorescent techniques (Dowling and Ehinger, 1978; Haggendal and Malmfors, 1963, 1965; Laties and Jacobwitz, 1966). Thus, the dopamine-accumulating amacrine cells in this retina probably also contain high levels of endogenous dopamine and are probably dopaminergic.

Release of $\left[{ }^{3} \mathrm{H}\right]$ dopamine in the adult retina. The ability of the dopamine-accumulating neurons to release the preloaded $\left[{ }^{3} \mathrm{H}\right]$ dopamine upon depolarization by high external $\mathrm{K}^{+}$was examined by an intraocular injection of $\left[{ }^{3} \mathrm{H}\right]$ dopamine $1 \mathrm{hr}$ prior to the release experiment. As shown in Figure 2, radioactivity can be released from the retina in response to $\mathrm{K}^{+}$stimulation. Furthermore, this release is probably $\mathrm{Ca}^{2+}$ dependent as it is inhibited by 5 to $10 \mathrm{mM} \mathrm{Co}{ }^{2+}$ in the medium. Upon removal of the $\mathrm{Co}^{2+}$, $\mathrm{K}^{+}$-rich Ringer's solution once again elicits a smaller but significant efflux of radioactivity from the retina. Product identification of the radioactivity in the retinas and eluates by high voltage paper electrophoresis showed that $96.1 \pm 2.0 \%$ of the radioactivity release in response to $\mathrm{K}^{+}$-rich Ringer's solution remained as $\left[{ }^{3} \mathrm{H}\right]$ dopamine. This result therefore shows that dopamine, and not its metabolic products, is released from dopamine-accumulating neurons by $\mathrm{K}^{+}$depolarization of the retina.
Dopamine content and tyrosine hydroxylase activity in the adult retina. In order to minimize any variations in endogenous dopamine levels due to circadian rhythm (Otten and Thoenen, 1975; Thoenen, 1970), rabbils were kept in a stable environment described under "Materials and Methods." They were sacrificed in the light-adapted state at about the same time of the day (2 P.M.). The retinas were isolated quickly, placed in isotonic medium, and frozen in liquid nitrogen within $1 \mathrm{~min}$ to minimize postmortem changes in dopamine content. Using the radioenzymatic assay described by Coyle and Hendry (1973), the endogenous dopamine content in adult rabbit retinas was found to be $2.2 \pm 0.3 \mu \mathrm{M}$.

The activities of tyrosine hydroxylase (TH), the ratelimiting enzyme for dopamine synthesis, were measured by methods modified from those of Nagatsu et al. (1964) and Coyle (1972). The retinas also were light adapted at the time of isolation to minimize possible activities in TH changes due to light stimulation (Iuvone et al., 1978). Under these conditions, the specific activity of TH in the adult rabbit retina was found to be $6.0 \pm 0.5 \mu \mathrm{mol} / \mathrm{gm}$ of protein/hr.

Monoamine oxidase in the adult retina. A method modified from that of Berrentini et al. (1978) was used to measure the specific activities of monoamine oxidase (MAO), the enzyme responsible for the degradation of dopamine. The specific activity of this enzyme in the adult rabbit retina was found to be $4.5 \pm 0.8 \mu \mathrm{mol}$ of dopamine degraded/gm of protein/hr. Since two distinct types of MAO, MAO-A and MAO-B, are known to exist in different tissues (Hall et al., 1969; Roth and Gillis, 1975) and follow different developmental patterns (Bourgoin et al., 1977; McCaman and Aprison, 1964), the characteristics of MAO in the rabbit retina were further examined pharmacologically by using specific inhibitors 
of MAO-A (clorgyline) and MAO-B (deprenyl), respectively. In the first study, dopamine, which is a common substrate for both MAO-A and MAO-B, was used as the substrate. As shown in Figure 3, MAO activity in the retina is only partially inhibited even at relatively high concentrations of deprenyl $\left(10^{-5}\right.$ to $\left.10^{-7} \mathrm{M}\right)$. However, in this concentration range, clorgyline inhibits MAO activity by over $95 \%$. The $\mathrm{IC}_{50}$ for deprenyl is $1.17 \times 10^{-5} \mathrm{M}$, whereas that of clorgyline is $2.92 \times 10^{-10}$ M. Thus, clorgyline is over $10^{4}$ times more effective in the inhibition of MAO activities in the rabbit retina. Furthermore, the dose-response plot shown in Figure 3 is of a single sigmoidal rather than double sigmoidal shape, indicating that there is only one type of MAO in the rabbit retina.

Glover et al. (1977) have shown that dopamine may not be a common substrate for MAO in certain tissues. We therefore used tryptamine, another common substrate for MAO, to characterize this enzyme in the retina.
As shown in Figure 4, using tryptamine as a substrate, deprenyl is even less effective in inhibiting MAO activity, while clorgyline remains a potent inhibitor. Under these conditions, the $\mathrm{IC}_{50}$ for deprenyl is $2.51 \times 10^{-4} \mathrm{M}$, while that for clorgyline is $5.37 \times 10^{-10} \mathrm{M}$. Thus, clorygyline is over $10^{5}$ times more potent in the inhibition of MAO activities. Once again, no point of inflection is present in these plots, indicating that the MAO in the rabbit retina is only or predominantly of the type MAO-A.

In another set of experiments, benzylamine, a MAOB-specific substrate, was used for the assay of MAO activities. The change in the absorbance due to the formation of benzaldehyde is extremely small and approaches 0 for the same enzyme dilution as in the former enzyme assays using dopamine and tryptamine as substrates. This result further demonstrates a lack of MAO$B$ activities in the rabbit retina.

Localization of $\left[{ }^{3} \mathrm{H}\right]$ dopamine uptake during retinal

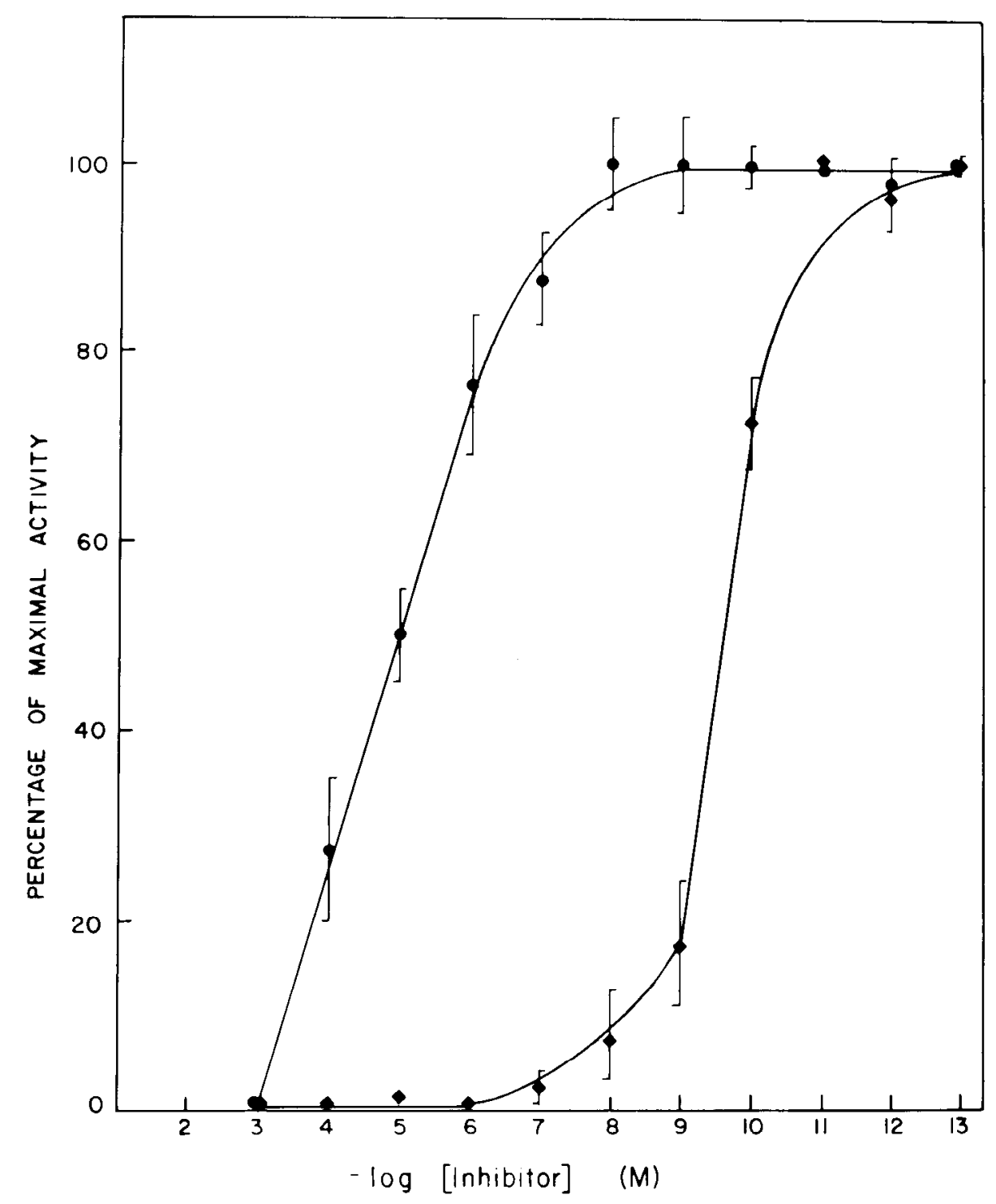

Figure 3. Clorgyline $(\diamond)$ and deprenyl $(\bullet)$ inhibitions of MAO activities in adult rabbit retinas using dopamine as the substrate. $\mathrm{IC}_{50}$ designates the concentration of the inhibitor required for $50 \%$ inhibition of the enzyme activity. Bars represent SEM $(n=3)$. 


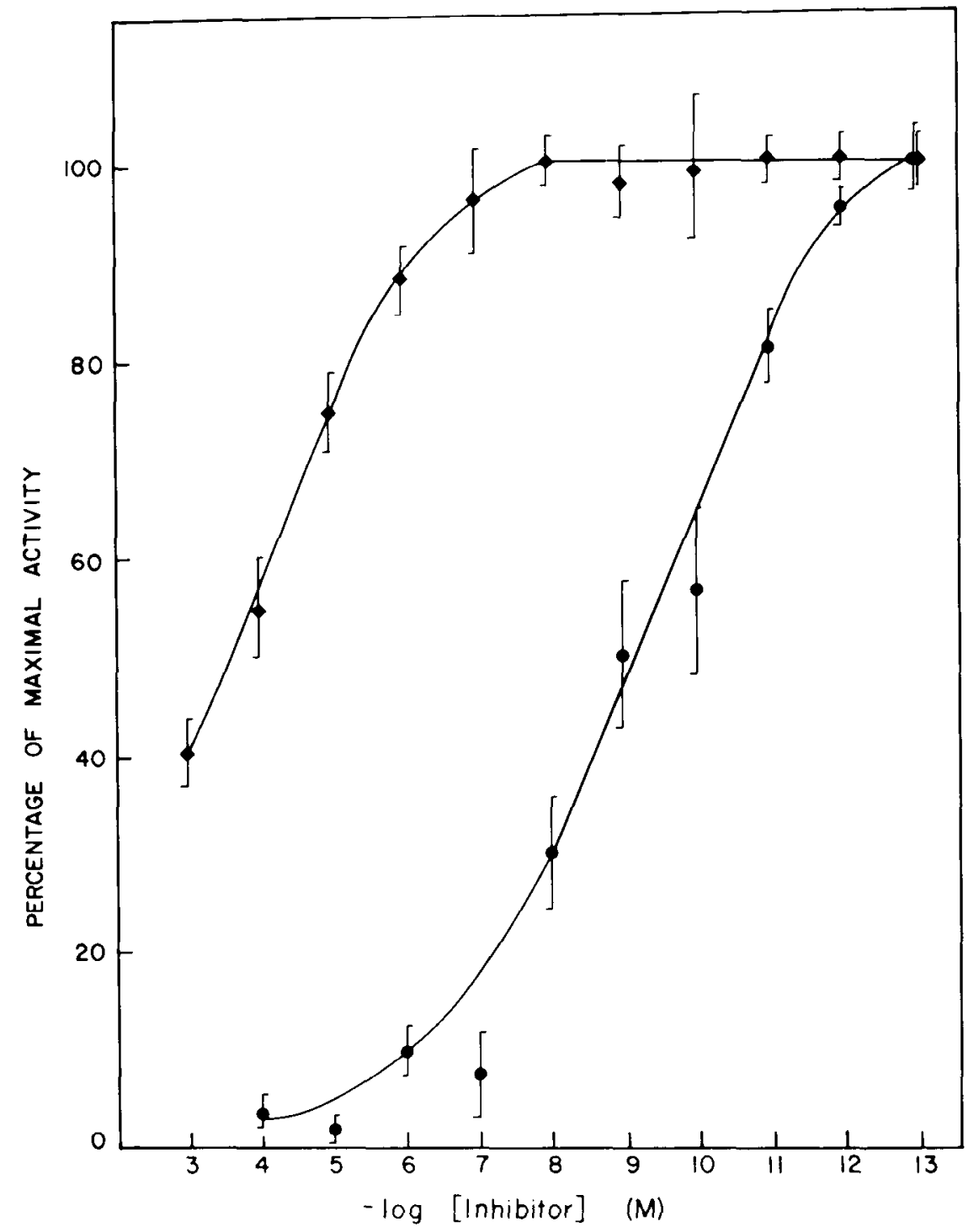

Figure 4. Clorgyline ( ) and deprenyl ( $)$ inhibitions of MAO activities in adult retinas using tryptamine as the substrate. ${ } C_{50}$ designates the concentration of the inhibitor required for $50 \%$ inhibition of the enzyme activity. Bars represent SEM $(n=3)$.

development. The uptake of $\left[{ }^{3} \mathrm{H}\right]$ dopamine by retinal cells following injections of $\left[{ }^{3} \mathrm{H}\right]$ dopamine into the eyes of 1-day-old animals is shown in Figure 5a. Although there is a distinct inner plexiform layer, the retina at this age is morphologically and physiologically immature (Kong et al., 1980; Lam et al., 1979; Masland, 1977; McArdle et al., 1977). There are still some mitotic figures and no outer segments. Nevertheless, distinctly labeled dopamine-accumulating cells are present in the newborn retina, indicating that these cells already possess a specific mechanism for dopamine uptake. Additionally, similar to the labeling pattern for dopamine uptake in the adult retina, within the inner plexiform layer, there is a sharp band of labeled processes adjacent to the inner nuclear layer (Fig. 5a). The morphology, pattern of lamination, and density of these labeled cells are similar to dopamine-accumulating cells of the adult retina. These results suggest that the commitment for certain neurons in the rabbit retina to be dopaminergic is made at, or prior to, birth.

At 4 days after birth, the retina is still immature, but the cells are less elongated and there is a clearly defined outer plexiform layer (Fig. $5 b$ ). The band of dopamineaccumulating processes in the inner plexiform is also more distinct. Once again, the morphology and density of dopamine-accumulating cells at this developmental stage are very similar to those of the adult as well as the 1-day-old retina, indicating that these cells are most likely destined to be dopaminergic neurons. Furthermore, the paucity of the dopaminergic somas, despite the presence of a distinct band of labeled processes in the 4-dayold retina, suggests that these neurons already have extensive arborizations at this stage.

Release of $\left[{ }^{3} \mathrm{H}\right]$ dopamine during retinal development. Since our autoradiographic results show that dopamineaccumulating neurons are already present and identifia- 

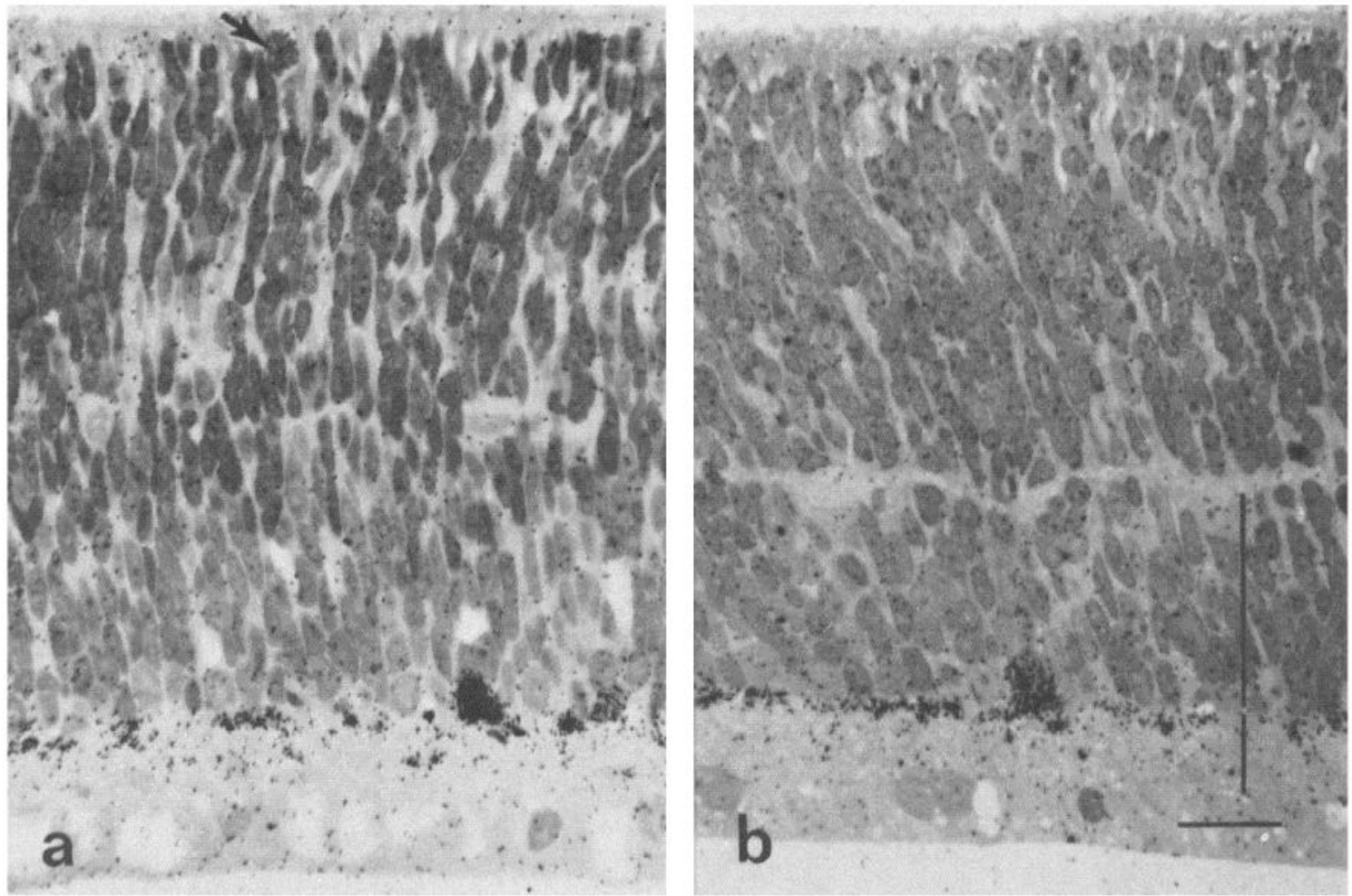

Figure 5. Autoradiographs of developing rabbit retinas $1 \mathrm{hr}$ after an intraocular injection of $50 \mu \mathrm{Ci}$ of $\left[{ }^{3} \mathrm{H}\right]$ dopamine. $a$, 1-day-old retina. Although there is a fairly distinct inner plexiform (arrow) layer, the retina is morphologically immature. There are still some mitotic figures (arrow) and no outer segments; the cells are fairly elongated and the retina is much thicker than the adult retina. Nevertheless, labeled somas are obviously located in the vitreal side of the inner nuclear layer. Additionally, similar to the adult retina, labeled processes in the inner plexiform layer are concentrated in a band adjacent to the inner nuclear layer. $b, 4$-day-old retina. The somas in the inner nuclear layer are more rounded. The morphology and distributions of labeled somas and their arborizations resemble dopamine-accumulated amacrine cells in the adult retina. The maturing inner nuclear layer and inner plexiform layer are denoted by the upper and lower vertical bars, respectively. Scale bar, $20 \mu \mathrm{m}$.

ble at birth, the emergence and maturation of $\mathrm{K}^{+}$-stimulated $\mathrm{Ca}^{2+}$-dependent release of dopamine from these cells can be studied throughout postnatal development by preloading them with $\left[{ }^{3} \mathrm{H}\right]$ dopamine. As shown in Figure $6, \mathrm{~K}^{+}$-stimulated $\mathrm{Ca}^{2+}$-dependent release of the accumulated $\left[{ }^{3} \mathrm{H}\right]$ dopamine is observed even in the newborn retina. However, under our experimental conditions, the rate of dopamine release from the newborn retina is only about $40 \%$ that of the adult. This finding indicates that the release mechanism may only be partially mature or that there are fewer dopamine release sites at birth. The rate of $\left[{ }^{3} \mathrm{H}\right]$ dopamine release increases steadily to about $75 \%$ of the adult level by day 10 and reaches the adult level by day 14 .

Dopamine content and tyrosine hydroxylase activities during retinal development. The endogenous levels of dopamine in developing retinas were measured using a method identical to that for adult retina. As shown in Figure 7, dopamine levels in the retina are fairly low for the first 6 days after birth. From day 6 to day 9, the dopamine concentration increases slightly, but significantly, to about $30 \%$ of the adult level $(0.65 \mu \mathrm{M})$ and is maintained at this level for the next 10 days. At day 18, there is another abrupt increase in retinal dopamine concentrations, reaching about $50 \%$ of the adult level on day 21 and $100 \%$ by day 25 .

The biphasic pattern in the maturation of retinal dopamine contents is matched closely by the increase in TH activities. As shown in Figure 7, the activity of this enzyme in newborn retinas is extremely low (about 10 $\mathrm{nmol} / \mathrm{gm}$ of protein $/ \mathrm{hr}$ ). This low activity is maintained until day 6 when it increases to about $15 \%$ of the adult level by day 9 . This level rises very slowly until about day 18 when there is a large abrupt increase, reaching the adult level by about day 25 . These results suggest that there is a close correlation between the dopamine concentrations and TH activities during retinal development.

Kinetics of tyrosine hydroxylase activities during retinal development. The emergence and maturation of TH activities during retinal development were investigated further by kinetic studies of this enzyme. Figure 8 is a Lineweaver-Burk plot for the kinetic studies of TH activities in day 8 and adult retinas. The experimental data for newborn retinas are not shown because the TH activity at this stage is too low to ensure reliability. The apparent $K_{m}$ values for TH in day 8 and adult retinas are identical and equal $1.1 \times 10^{-4} \mathrm{M}$. On the contrary, the 
values of $V_{\max }$ in these two stages are vastly different. The $V_{\max }$ for TH in day 8 retina is $28.6 \mathrm{nmol} / \mathrm{gm}$ of protein $/ \mathrm{hr}$, while that for the adult retina is $571 \mathrm{~mol} / \mathrm{gm}$ of protein $/ \mathrm{hr}$. These findings indicate that there is a large increase in functionally active $\mathrm{TH}$ in the retina during postnatal development. It is not known, however, whether this increased activity is due to an increase in the synthesis of $\mathrm{TH}$ or a transition from an inactive form of the enzyme to a functional form.

Monoamine oxidase activities during retinal development. Contrary to the development patterns of dopamine uptake, release, content, and synthesis, the specific activity of MAO in the newborn retina is about $300 \%$ of that found in the adult retina (Fig. 9). The high MAO activities are maintained for the first 6 days after birth, and decrease dramatically to $150 \%$ of the adult level by day 11 . There is then a gradual decline in MAO activity, reaching the adult level by day 25 . These results show that MAO is clearly present in the rabbit retina at high levels throughout postnatal life. Indeed, this enzyme is highly active prior to the presence of significant levels of endogenous dopamine or tyrosine hydroxylase activities in the retina.

Kinetics of monoamine oxidase activities during retinal development. Similar to our analyses of TH activities, we have examined the kinetic properties of MAO in day 1, day 8, and adult retinas. As shown in Figure 10, the apparent $K_{m}$ for MAO, $0.267 \mathrm{mM}$, is the same for all three stages. In contrast, the $V_{\max }$ values of MAO in day 1 , day 8 , and adult retinas are $20,11.76$, and $4.76 \mu \mathrm{mol}$ of dopamine degraded/gm of protein/hr, respectively. This decrease in $V_{\max }$ probably accounts for the decline in MAO activities during retinal development. Additionally, our findings that the Lineweaver-Burk plots were linear and the apparent $K_{m}$ was unchanged for all three stages agree with our pharmacological characterization of MAO and indicate that only one form of MAO is present in both developing and adult rabbit retinas, namely, the type A form of MAO.

\section{Discussion}

Dopaminergic neurons in the rabbit retina. There is considerable evidence that dopamine is a neurotransmitter in the vertebrate retina. By means of a histofluorescence technique, Haggendal and Malmfors (1963, 1965) were the first investigators to identify and localize dopamine-containing neurons in the rabbit retina. Subsequently, dopamine has been shown to be present and localized in identified neurons of all retinas that have been examined to date (Dowling and Ehinger, 1978; Ehinger, 1977; Ehinger and Floren, 1978; Graham, 1974; Kato et al., 1980; Laties and Jacobwitz, 1966). Certain retinal neurons also have been shown to possess a high affinity mechanism for dopamine uptake and to release

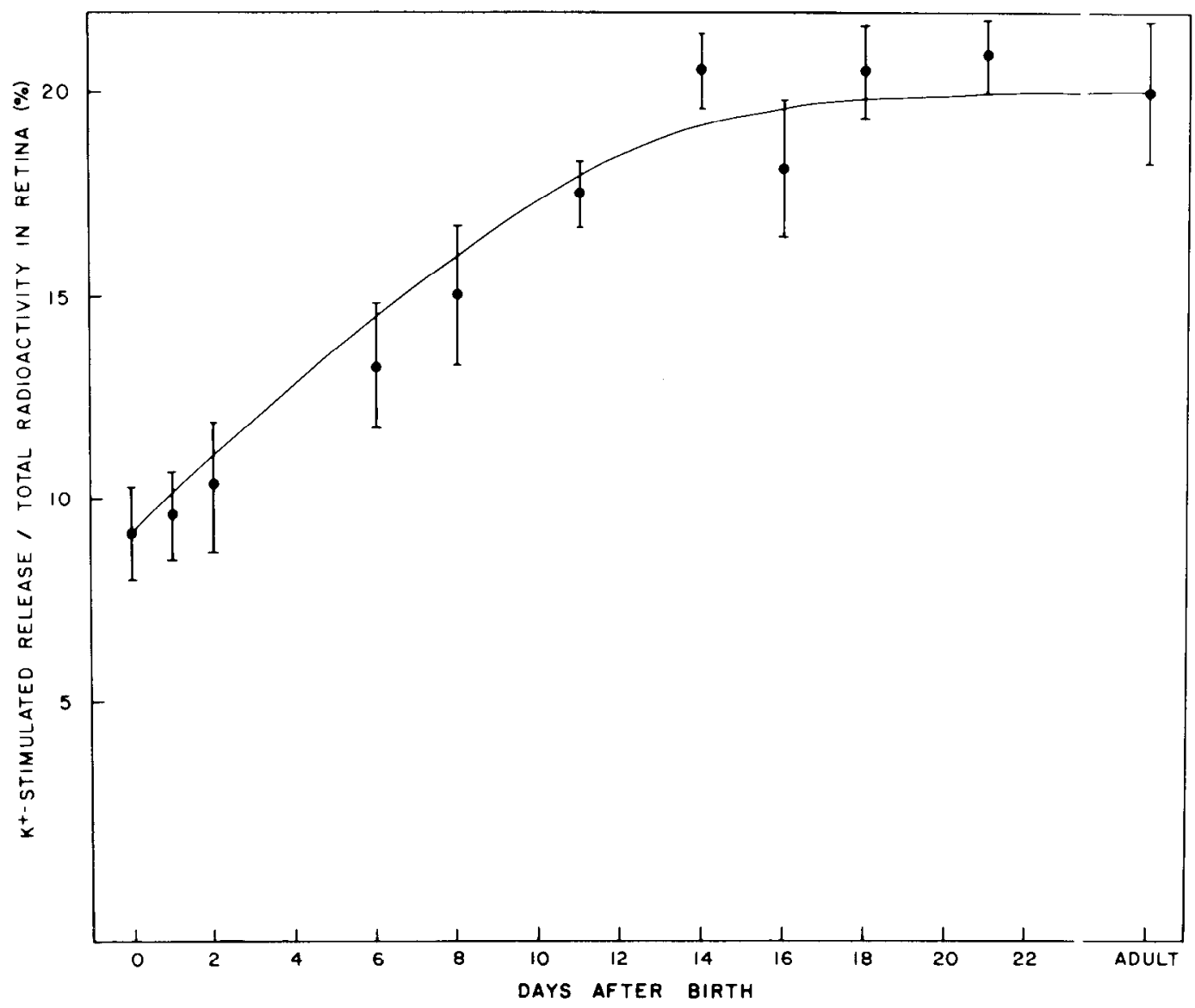

Figure 6. $\mathrm{K}^{+}$-stimulated $\mathrm{Ca}^{2+}$-dependent release of $\left[{ }^{3} \mathrm{H}\right]$ dopamine from retinas at different days of postnatal development. Bars designate SEM $(n \leq 3)$. 


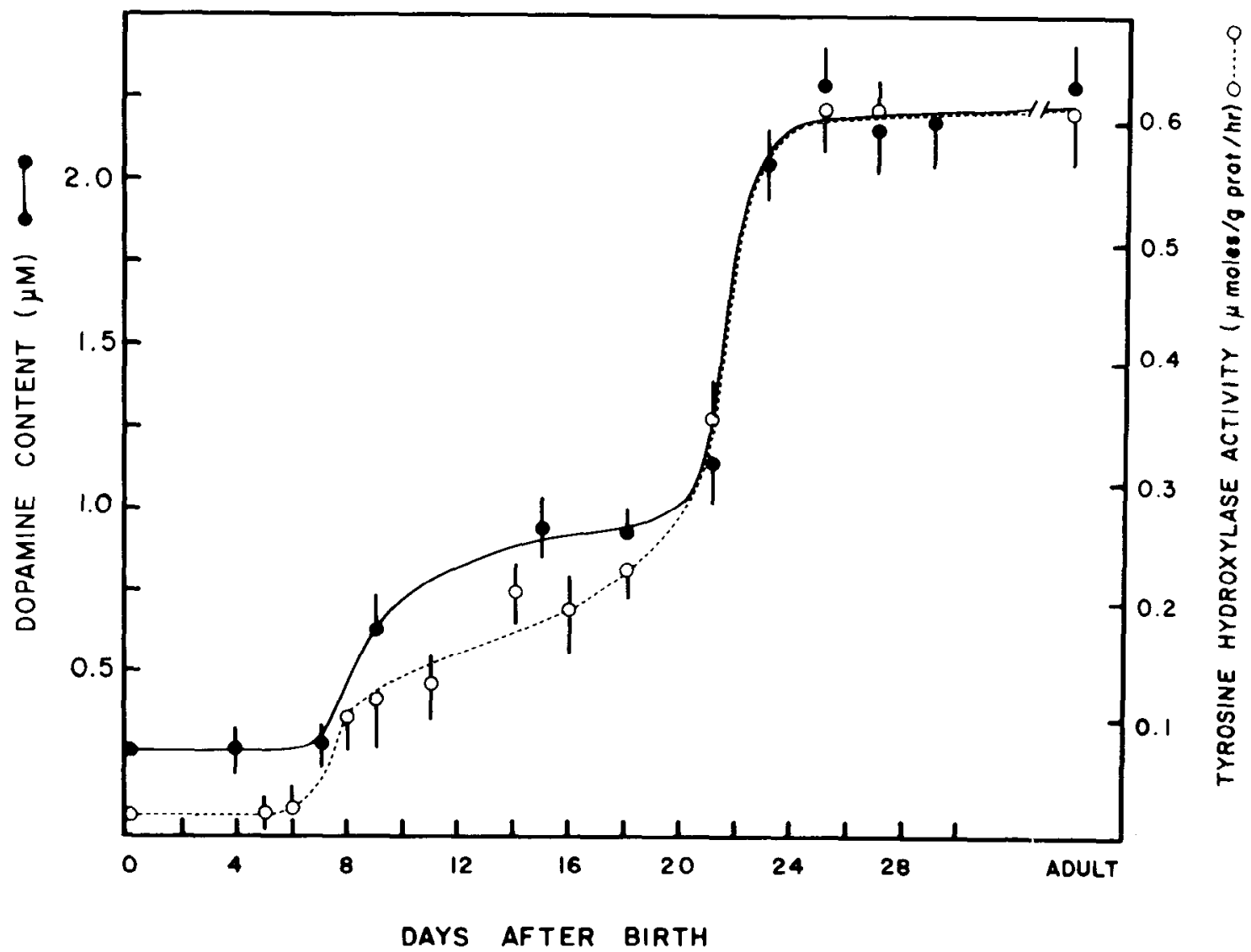

Figure 7. Specific activities of tyrosine hydroxylase (O) and dopamine concentrations (O) in rabbit retinas at different days of postnatal development. Bars represent SEM $(n \leq 3)$.

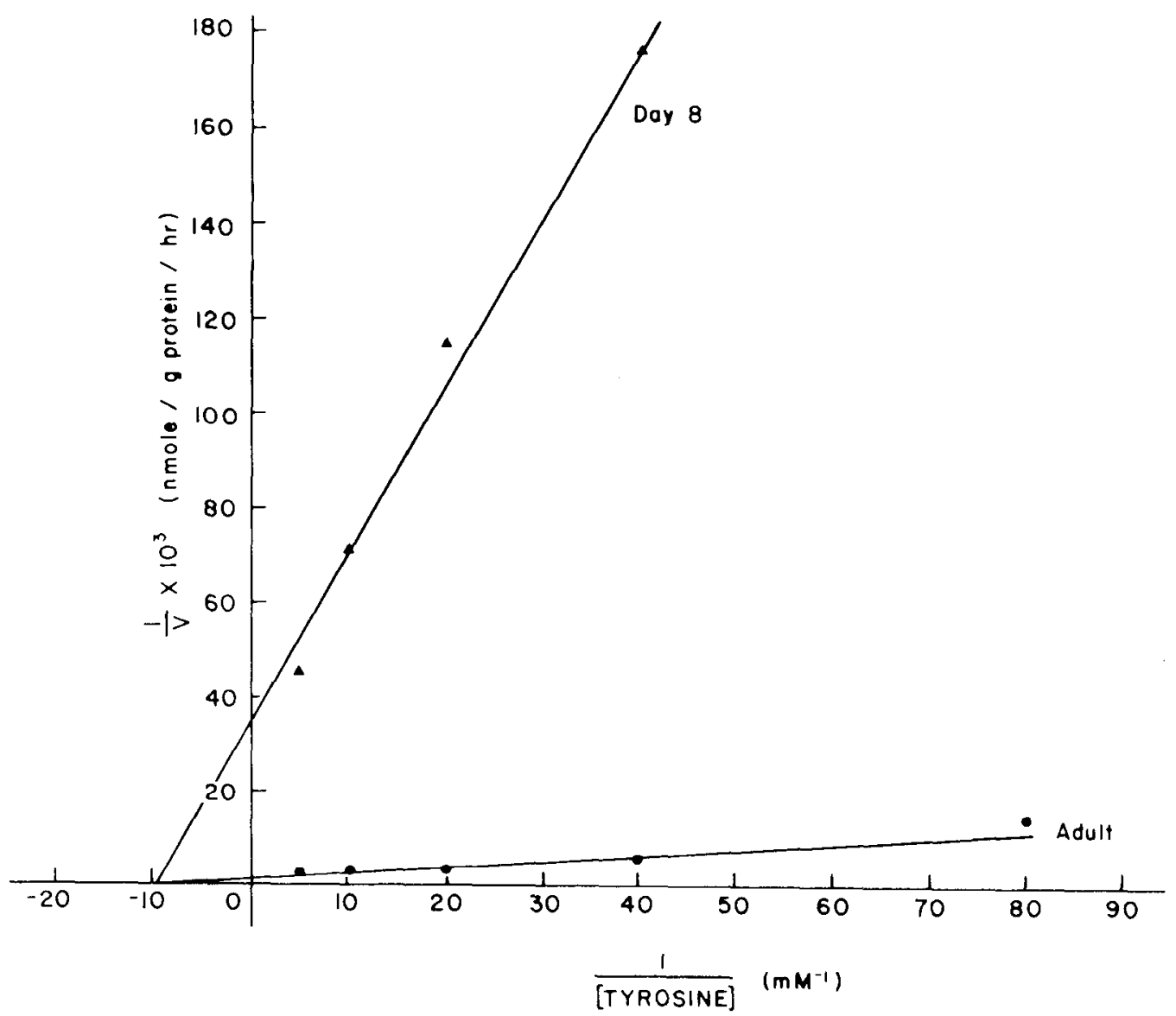

Figure 8. Lineweaver-Burk plots for tyrosine hydroxylase activities in 8-day-old and adult retinas. The activities of tyrosine hydroxylase were assayed in $1 \mathrm{M}$ potassium phosphate buffer (pH 6) at $37^{\circ} \mathrm{C}$. Enzyme preparations were supernatants of retinal homogenates after centrifugation at $10,000 \times \mathrm{g}$ for $10 \mathrm{~min}$. Each point represents the average of two assays. 


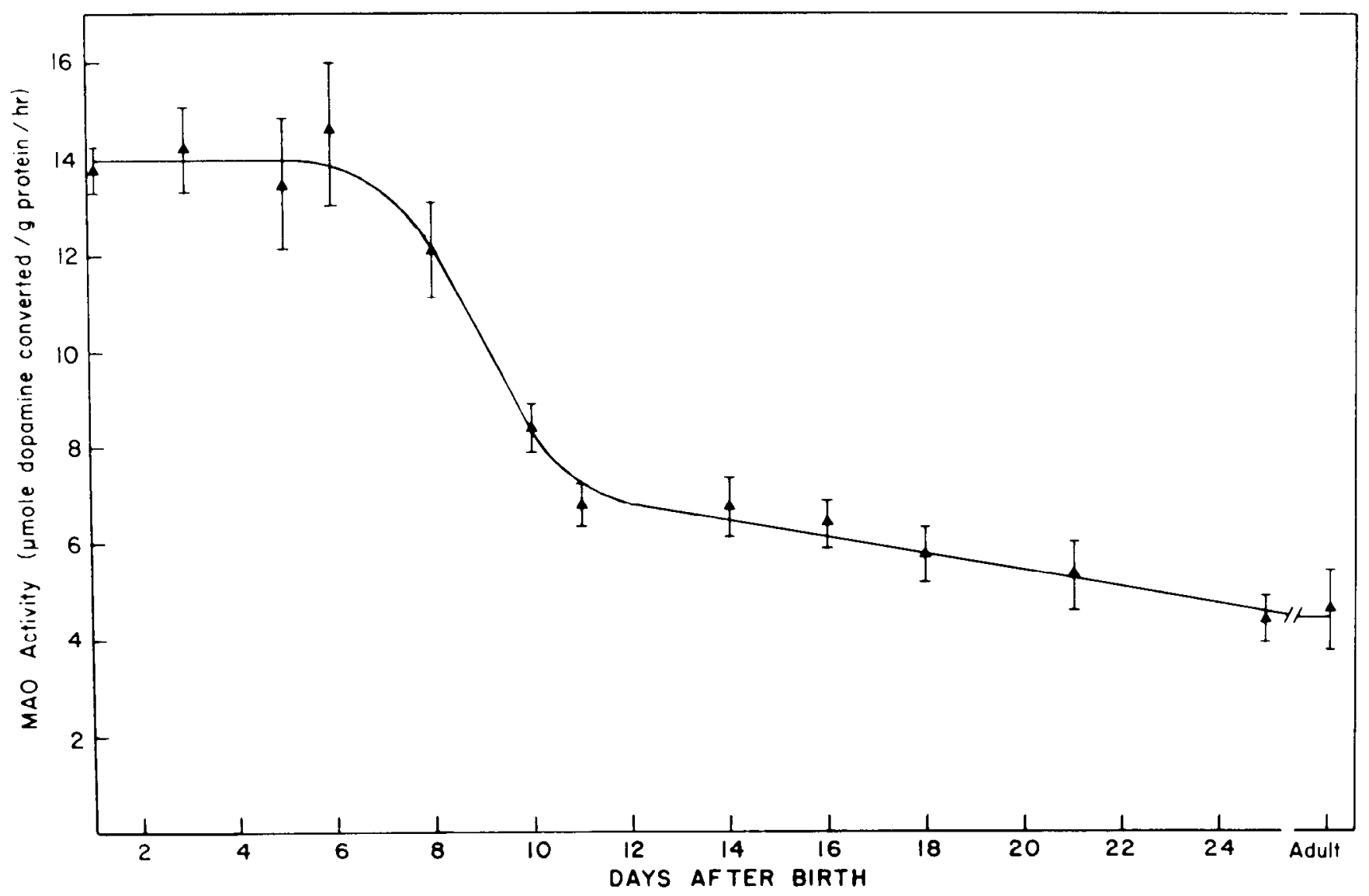

Figure 9. Specific activities of MAO in rabbit retinas at different days of postnatal development. Bars represent SEM ( $n \leq 3$ ).

the accumulated dopamine upon stimulation by light or high external $\mathrm{K}^{+}$(Kramer, 1971; Kramer et al., 1971; Sarthy and Lam, 1979; Sarthy et al., 1981). Additionally, electrophysiological studies have shown that dopamine and its analogues have potent and reversible effects on the activities of retinal neurons (Ames and Pollen, 1969; Hedden and Dowling, 1978; Negishi and Drujan, 1978) and putative postsynaptic dopamine receptors in the retina have been identified (Thomas et al., 1978; Redburn et al., 1980; Schorderet and Magistretti, 1980; Watling et al., 1980).

The results presented in this paper confirm earlier findings that, in the rabbit retina, certain neurons with a morphology and distribution similar to the dopaminecontaining amacrine cells possess a high affinity mechanism for dopamine uptake and release the accumulated dopamine in response to depolarization by high external $\mathrm{K}^{+}$. These putative dopaminergic neurons represent a type of amacrine cell which ramifies predominantly as a sharp band adjacent to the inner nuclear layer with punctate terminals occasionally extending to deeper regions of the inner plexiform layer. These cells have been shown by electron microscopy to be pre- and postsynaptic to other amacrine cells exclusively (Dowling and Ehinger, 1978; Ehinger, 1977). Compared to the number of putative GABAergic (about 49 somas $/ \mathrm{mm}$ of linear expanse) and glycinergic (about 70 somas $/ \mathrm{mm}$ ) amacrine cells, the density of dopaminergic neurons (0.4 to 1.2 somas $/ \mathrm{mm}$ ) in the rabbit retina is very low. Thus, al- though the functional roles of dopaminergic cells in the rabbit retina are unknown, the sparsity of these cells suggests that they have extensive processes and, unlike GABAergic and glycinergic amacrine cells, may play a role in the integration of visual information over a vast retinal expanse.

Dopamine-accumulating cells in developing retinas. In the newborn rabbit retina, there is already a population of cells that selectively takes up exogenously supplied dopamine. The number, position, and morphology of these cells suggest that they are likely to become dopaminergic neurons of the adult retina. Thus, similar to the specific neuronal uptake systems for GABA and glycine (Kong et al., 1980; Lam et al., 1980), the dopamine uptake mechanism in dopaminergic neurons of the rabbit retina is functional at, or prior to, birth. This finding suggests that, like GABAergic and glycinergic neurons, the commitment by certain neurons to be dopaminergic also is made prenatally. Prenatal studies are in progress to determine the temporal sequence for the emergence and maturation of the uptake mechanisms for GABA, glycine, and dopamine.

Additionally, even in the 1-day-old retinas, numerous labeled punctate terminals are evident (Fig. $5 a$ ), indicating that the dopamine-accumulating cells probably already have extensive processes at this stage. In an earlier study, we have shown that, when isolated goldfish retinas were incubated with $\left[{ }^{3} \mathrm{H}\right]$ dopamine for various periods of time, the presynaptic terminals of dopaminergic neurons 


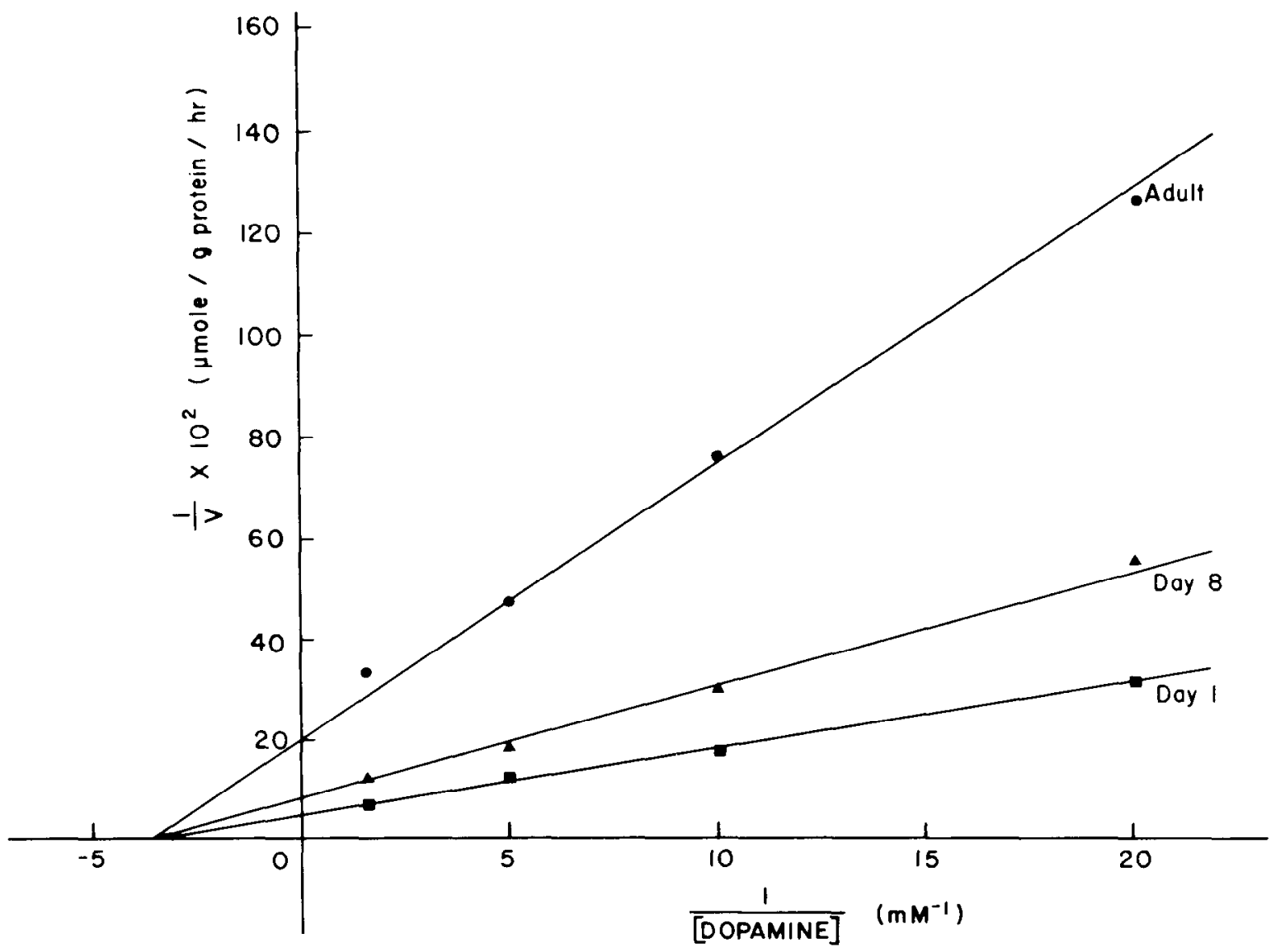

Figure 10. Lineweaver-Burk plots of MAO activities in day 1 , day 8 , and adult retinas. MAO activities were assayed by the oxidative deamination of dopamine. Enzyme preparations were supernatants of retinal homogenates after centrifugation at 2,000 $\times \mathrm{g}$ for $2 \mathrm{~min}$. Each point represents the average of two assays.

were labeled much earlier than the corresponding somas (Sarthy and Lam, 1979). This result suggests that the uptake sites for dopamine may be predominantly on the presynaptic terminal rather than on the somas. The sites of dopamine transport in the rabbit retina are, unfortunately, not known. It is therefore of interest to examine by electron microscopy autoradiography the morphology and synaptic structure of putative dopaminergic cells in newborn and postnatal rabbit retinas.

The functional roles played by the dopamine uptake mechanism also are unknown. By analogy with the possible role of noradrenaline uptake in adrenergic transmission (Iversen, 1976), dopamine uptake may be an effective mechanism for the clearance and inactivation of the dopamine released during synaptic transmission. Additionally, the uptake of dopamine into presynaptic dopaminergic terminals following its release may decrease the need for its synthesis and degradation during prolonged neuronal stimulation.

Dopamine release during retinal development. Not only do certain cells in the newborn rabbit retina possess a high affinity mechanism for dopamine uptake, they also can release the accumulated dopamine in response to a $\mathrm{Ca}^{2+}$-dependent $\mathrm{K}^{+}$depolarization. In our earlier studies on the development of the amino acid transmitter system, GABA and glycine, we showed that, although putative GABAergic and glycinergic neurons in the rab- bit retina already possess specific mechanisms for GABA and glycine uptake, respectively, at birth, the accumulated GABA and glycine are not released significantly by $\mathrm{Ca}^{2+}$-dependent $\mathrm{K}^{+}$stimulation until 7 to 9 days after birth (Kong et al., 1980; Lam et al., 1980). Thus, during development of the rabbit retina, the release mechanism for dopamine is functional much earlier than that for GABA and glycine. It is not known, however, whether the release of transmitters under our experimental conditions represents true synaptic and vesicular release. In this regard, it is of interest to compare the developmental patterns of presynaptic terminals or putative GABAergic, glycinergic, and dopaminergic neurons during retinal morphogenesis by a combination of high affinity uptake studies and electron microscopy autoradiography.

Dopamine concentrations and tyrosine hydroxylase activities in the developing retina. Our results show that, during postnatal development of the rabbit retina, the dopamine contents increase at a rate very similar to the rise in the specific activities of $\mathrm{TH}$, the rate-limiting enzyme for dopamine synthesis. This close correlation, together with our findings on retinal MAO activities, suggests that dopamine concentrations in the developing retina are regulated primarily through the biosynthesis of dopamine. Both the dopamine contents and TH activities fail to reach adult levels until about 25 days after birth. In the rat retina, Kato et al. (1980) also have shown 
by a histofluorescence technique that the dopaminergic neurons appear fully developed by about the 28th day after birth.

Our studies also indicate that both dopamine concentrations and TH activities in the developing retina reach the adult level in a distinctly biphasic pattern. Although the functional significance of this maturation pattern is unknown, our results suggest that certain intrinsic programs and/or extrinsic factors may regulate the increase in tyrosine hydroxylase activities at two precise stages during retinal development: the first, between days 6 and 8 and the second, between days 18 and 24. In this regard, it is of interest that Stanton et al. (1974) also reported a two-phase increase in tyrosine hydroxylase activity during development of swine superior cervical ganglion. The activity in the newborn pig was about $10 \%$ of the adult level, increasing slowly during the subsequent 14 days to about $20 \%$ of the adult level, then rising sharply between day 14 and day 39 to about $95 \%$ of the adult level. The biphasic increase in the postganglionic fiber was tentatively explained in conjunction with the emergence of the choline acetyltransferase (CAT) activities in the preganglionic fiber. Since CAT activity was nearly maximal by day 14 , the second phase of increase in $\mathrm{TH}$ activity that begins on day 14 was attributed to the influence of cholinergic input which, by this time, was assumed to be mature. In contrast, the first phase of increase appeared to be independent of synaptic formation and, therefore, might reflect the rise in TH activities in the absence of extrinsic influences. The trophic effect of acetylcholine on the development of the postganglion adrenergic fiber also has been examined by Thoenen (1972), who showed that denervation of the preganglionic cholinergic fiber during the critical period of development causes a delay in the maturation of the postganglionic fiber.

It is not known whether similar induction of $\mathrm{TH}$ activities occur during retinal development. Furthermore, although dopaminergic amacrine cells in the rabbit retina are known to receive input from other amacrine cells (Dowling and Ehinger, 1978), the neurotransmitters used by these cells are not known. However, electron microscopic studies on the synaptogenesis of amacrine contacts revealed that the synaptic density was about $20 \%$ of the adult level for the first 9 days after birth, then increased steadily to $75 \%$ by day 12 , and reached the adult level by day 20 (McArdle et al., 1977). Of the three neurotransmitter systems so far examined, putative GABAergic, glycinergic, and cholinergic amacrine cells

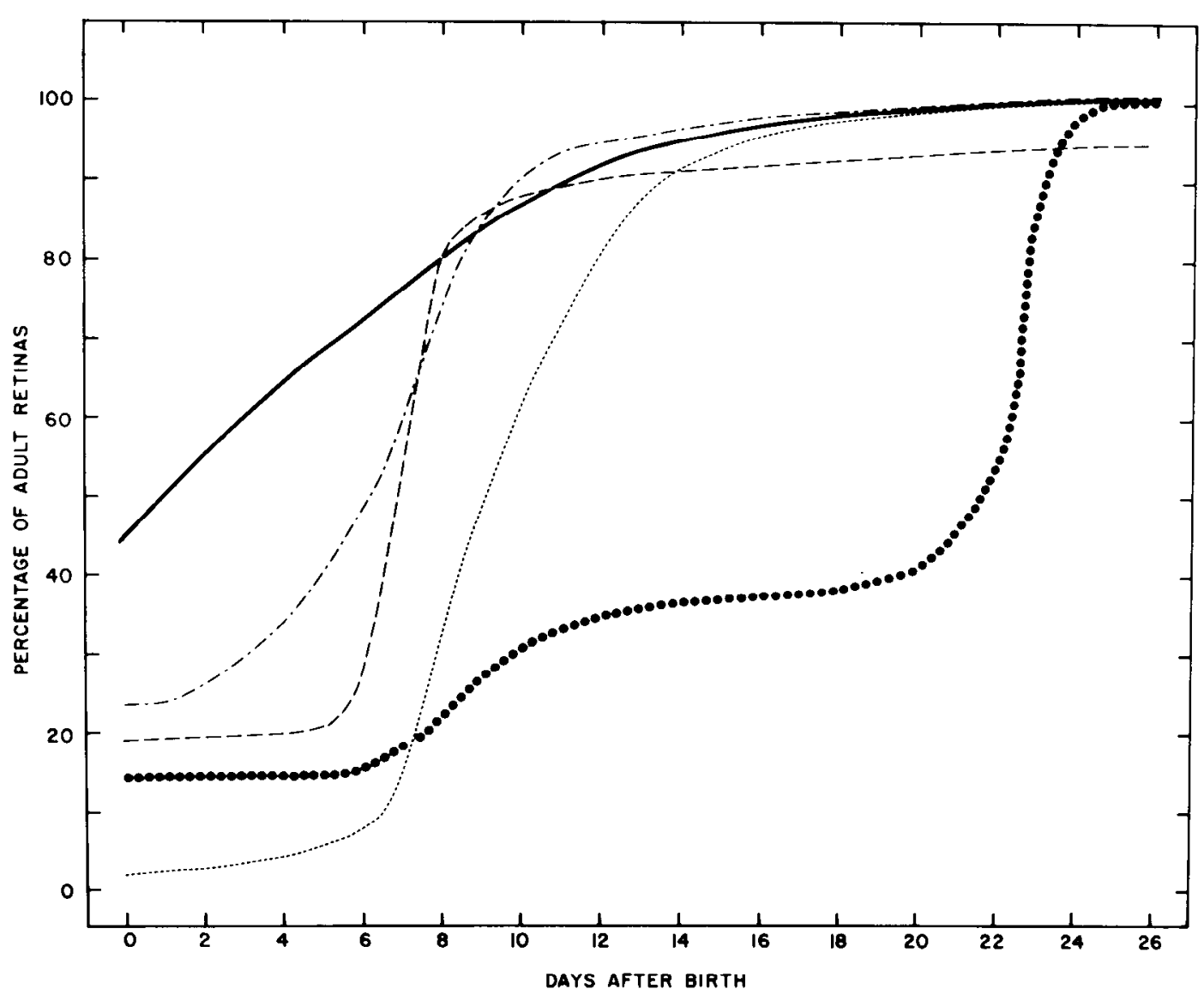

Figure 11. A comparison of the development patterns of endogenous dopamine concentrations $(\ldots .$.$) and \left[{ }^{3} \mathrm{I}\right]$ dopamine release $(\cdots-)$ with those of endogenous GABA concentrations $(-\cdot \cdot \cdot-)$, $\left[{ }^{3} \mathrm{H}\right]$ GABA release $(---)$, and $\left[{ }^{3} \mathrm{H}\right]$ glycine release $(-.-)^{-}$in the rabbit retina. The releases of ${ }^{3} \mathrm{H}$ neurotransmitter candidates were measured by $\mathrm{Ca}^{2+}$-dependent effluxes of preloaded ${ }^{3} \mathrm{H}$ transmitters into the medium in response to $56 \mathrm{mM}$ extracellular $\mathrm{K}^{+}$. Results of the studies on GABA and glycine are taken from our earlier studies (Kong et al., 1980; Lam et al., 1980). 
are quite immature at 6 days after birth and are therefore unlikely to induce the increase in tyrosine hydroxylase activities observed at this stage (Kong et al., 1980; Lam et al., 1980; D. M. K. Lam, S. C. Fung, and Y. C. Kong, unpublished observations). In contrast, by day 18 , when the second phase of dramatic increase in $\mathrm{TH}$ activities was observed, GABAergic, glycinergic, and dopaminergic synapses are most probably functionally mature and some of these or other transmitter systems may indeed play a role in the induction of this enzyme and lead to the maturation of dopaminergic amacrine cells. In this regard, it may be of interest to examine the developmental pattern of $\mathrm{TH}$ and dopamine contents following the interference of transmission from identified retinal synapses.

$M A O$ activities during retinal development. The finding that only the A form of MAO (MAO-A) is present in the rabbit retina is quite different from other tissues in this animal. Both forms of MAO are found in the rabbit brain (Hall et al., 1969) and only the B form is found in the heart and lung (Roth and Gillis, 1975). Our results indicate that, in the rabbit retina, MAO activities are $300 \%$ of the adult level for the first 6 days after birth, decrease to $150 \%$ by day 11 , and reach the adult level at day 25. McCaman and Aprison (1964) have studied the MAO activities in the rabbit brain beginning 3 days after birth. At day 3, the enzymatic activity is equal or higher than that of the adult in the different parts of the brain. Since MAO in the rabbit brain has both forms of MAO, the presence of MAO-A may be responsible for the higher level of total MAO activity immediately after birth. This correlation was later substantiated by a similar study in the rat brain. Bourgoin et al. (1977) demonstrated that, in the rat brain, the MAO-A activity was higher during early life than in the adult. On the contrary, the MAO-B activity increased steadily from newborn to the adult brain.

The decrease in MAO-A activities during postnatal development of the retina and other tissues suggests that, in the neonatal retina, this enzyme may be related to some functions other than the biodegradation of dopamine because it is difficult to comprehend why the retina would contain such a high capacity to degrade endogenous dopamine when the dopamine concentration at birth is very low. 'The real functions of this enzyme in developing and adult retinas thus require further investigations.

General conclusions. The results presented in this paper show that certain neurons in the newborn rabbit retina possess a specific uptake system for dopamine and are likely to become dopaminergic neurons of the adult retina. Thus, similar to our earlier studies on the development of GABAergic and glycinergic neurons (Kong et al., 1980; Lam et al., 1980), the commitment for certain neurons to be dopaminergic is made prenatally. However, unlike GABA- and glycine-accumulating neurons in the newborn retina, dopamine-accumulating neurons in the newborn retina are capable of releasing a significant amount of the accumulated dopamine in response to $\mathrm{K}^{+}$ depolarization in a $\mathrm{Ca}^{2+}$-dependent manner. (Fig. 11). Furthermore, our autoradiographic studies indicate that, during the first few days of postnatal development, these dopamine-accumulating cells already have long processes and extensive arborization in the inner plexiform layer. These neurons are, however, functionally immature at this time because they contain little endogenous dopamine and extremely low tyrosine hydroxylase activities. The dopamine concentrations and tyrosine hydroxylase activities increase in parallel and in a biphasic manner, reaching the adult level at about day 25 . The reason for this biphasic mode of maturation is unknown. By analogy to developmental studies in other nervous tissues, the possibility that the second phase of dramatic increase in retinal tyrosine hydroxylase activities, which begins around day 18, may be dependent on induction from other neurons deserves further study.

Our studies also raise a number of other interesting questions regarding the logistics in the development of retinal neurons and their transmitter systems. For instance, it is puzzling that there is a 2- to 3-week delay in the maturation of the dopamine-synthesizing mechanism compared to the dopamine uptake and release mechanisms. Additionally, in previous studies (Kong et al., 1980; Lam et al., 1980), we have shown that retinal GABAergic and glycinergic neurons are probably functionally mature shortly after the animals first open their eyes (about day 10), results which are consistent with the physiological maturation of ganglion cells (Masland, 1977) and morphological maturation of synaptic connections (McArdle et al., 1977). For instance, Masland (1977) has shown that visual responsiveness, concentric field organizations, and directional selectivities of ganglion cells are mature between days 12 and 20 in the rabbit retina. Therefore, it is unclear why the dopaminergic neurons become mature many days after the maturation of GABAergic and glycinergic amacrine cells as well as most ganglion cells. In this regard, it also would be reasonable to compare the emergence and maturation of postsynaptic dopamine receptors with the differentiation of dopaminergic neurons. The logistics underlying the developmental pattern of dopaminergic neurons is, however, likely to remain unknown until the roles played by these neurons in the processing of visual information are elucidated. Finally, in the Xenopus retina, our studies also indicate that the dopaminergic neurons become mature at a much later stage than putative GABAergic and glycinergic neurons (Hollyfield et al., 1979; Rayborn et al., 1981; Sarthy et al., 1981). In this retina, however, the last dopaminergic property to emerge is the dopamine release mechanism (Sarthy et al., 1981). The results presented in this paper therefore show that the emergence and maturation of dopamine uptake, synthesis, and release mechanisms in different retinas may follow vastly different developmental patterns.

\section{References}

Ames, A., III, and D. A. Pollen (1969) Neurotransmission in central nervous tissues: A study of isolated rabbit retina. J. Neurophysiol. 32: 424-444.

Berrentini, W. H., W. Prozialeck, and W. H. Vogel (1978) Decreased platelet monoamine oxidase activity in chronic schizophrenia. Arch. Gen. Psychiatry 35: 600-605.

Bourgoin, S., F. Artand, J. Adrien, F. Hery, J. Glowinski, and M. Hamon (1977) 5-Hydroxytryptamine catabolism in the rat brain during ontogenesis. J. Neurochem. 28: 415-422. 
Brandon, C., D. M. K. Lam, Y. Y. T. Su, and J. -Y. Wu (1980) Immunocytochemical localization of GABA neurons in the rabbit and frog retina. Brain Res. Bull. 5: 21-29.

Coyle, J. T. (1972) Tyrosine hydroxylase in the rat braincofactor requirements, regional and subcellular distribution. Biochem. Pharmacol. 21: 1935-1944.

Coyle, J. T., and D. Hendry (1973) Catecholamines in fetal newborn rat brain. J. Neurochem. 21: 61-67.

Dowling, J. E., and B. Ehinger (1978) Synaptic organization of the dopaminergic neurons in the rabbit retina. J. Comp. Neurol. 180: 203-220.

Ehinger, B. (1977) Synaptic connections of the dopaminergic retinal neurons. Adv. Biochem. Psychopharmacol. 16: 299306.

Ehinger, B., and I. Floren (1978) Quantitation of the uptake of indolamines and dopamine in the rabbit retina. Exp. Eye Res. 26: 1-11.

Glover, V., M. Sandler, F. Owen, and G. J. Riley (1977) Dopamine is a monoamine oxidase $B$ substrate in man. Nature 265: $80-81$.

Graham, L. T. (1974) Comparative aspects of neurotransmitters in the retina. In The Eye, H. Dawson and L. T. Graham, eds., Vol. 6, Academic Press, New York.

Haggendal, J., and T. Malmfors (1963) Evidence of dopaminecontaining neurons in the retina of rabbits. Acta Physiol. Scand. 62: 295-296.

Haggendal, J., and T. Malmfors (1965) Identification and cellular localization of the catecholamines in the retina. Acta Physiol. Scand. 64: 58-66.

Hall, D. W. R., B. W. Logan, and G. H. Parsons (1969) Further studies on the inhibition of monoamine oxidase by $M$ and $B$ 9302 (clorgyline). I. Substrate specificity in various mammalian species. Biochem. Pharmacol. 18: 1447-1454.

Hedden, W. L., and J. E. Dowling (1978) The interplexiform cell system. II. Effects of dopamine on goldfish retinal neurons. Proc. R. Soc. Lond. (Biol.) 201: 27-55.

Hildebrand, J. G., D. Barker, E. Herbert, and E. Kravitz (1971) Screening for neurotransmitters: A rapid radiochemical procedure. J. Neurobiol. 2: 231-246.

Hollyfield, J. G., P. V. Sarthy, M. E. Rayborn, and D. M. K. Lam (1979) The emergence, localization and maturation of neurotransmitter system during development of the retina in Xenopus laevis. I. $\gamma$-Aminobutyric acid. J. Comp. Neurol. 188: 587-598.

Iuvone, P. M., C. L. Galli, and N. H. Neff (1978) Retinal tyrosine hydroxylase: Comparison of short-term and long-term stimulation by light. Mol. Pharmacol. 14: 1212-1219.

Iversen, L. L. (1976) Inactivation of neurotransmitters. In Synapses, G. A. Cottrell and P. N. R. Usherwood, eds., pp. 137153, Plenum Press, New York.

Johnston, J. P. (1968) Some observations upon a new inhibitor of monoamine oxidase in brain tissue. Biochem. Pharmacol. 17: 1285-1287.

Kato, S., T. Nakamuya, and K. Negishi (1980) Postnatal development of dopaminergic cells in the rat retina. J. Comp. Neurol. 191: 227-236.

Knoll, J., and K. Magyar (1972) Monoamine oxidase-new vistas. Adv. Biochem. Psychopharmacol. 5: 393-408.

Kong, Y. C., S. C. Fung, and D. M. K. Lam (1980) The postnatal development of glycinergic neurons in rabbit retina. $J$. Comp. Neurol. 193: 1127-1135.

Kramer, S. G. (1971) Dopamine: A retinal neurotransmitter. I. Retinal uptake, storage and light-stimulated release of ${ }^{3} \mathrm{H}$ dopamine in vivo. Invest. Ophthalmol. Vis. Sci. 10: 438-452.

Kramer, S. G., A. M. Potts, and Y. Mangnall (1971) Dopamine: A retinal neurotransmitter. II. Autoradiographic localization of $\left({ }^{3} \mathrm{H}\right)$ dopamine in the retina. Invest. Ophthalmol. Vis. Sci. 10: $617-624$.
Lam, D. M. K. (1976) Synaptic chemistry of identified cells in the vertebrate retina. Cold Spring Harbor Symp. Quant. Biol. 40: 571-579.

Lam, D. M. K., Y. Y. T. Su, L. Swain, R. E. Marc, C. Brandon, and J. -Y. Wu (1979) Immunocytochemical localization of glutamic acid decarboxylase in the goldfish retina. Nature 278: 565-567.

Lam, D. M. K., S. C. Fung, and Y. C. Kong (1980) The postnatal development of GABA-ergic neurons in the rabbit retina. J. Comp. Neurol. 193: 89-102.

Laties, A. M., and D. Jacobwitz (1966) A comparative study of the autonomic innervation of the eye in monkey, cat and rabbit. Anat. Rec. 156: 383-396.

Lowry, O. H., N. J. Rosebrough, A. L. Farr, and R. J. Randall (1951) Protein measurement with the Folin phenol reagent. J. Biol. Chem. 193: 265-275.

Masland, R. H. (1977) Maturation of function in the developing rabbit retina. J. Comp. Neurol. 175: 275-286.

McArdle, C. B., J. E. Dowling, and R. E. Masland (1977) Development of outer segments and synapses in the rabbit retina. J. Comp. Neurol. 175: 253-274.

McCaman, R. E., and M. H. Aprison (1964) The synthesis and catabolic enzyme systems for acetylcholine and serotonin in several discrete areas of the developing rabbit brain. Prog. Brain Res. 9: 220-223.

McEwen, C. M., and J. D. Cohen (1963) An amine oxidase in normal human serum. J. Lab. Clin. Med. 62: 766-770.

Nagatsu, T., M. Levitt, and S. Udenfriend (1964) Tyrosine hydroxylase-initial step in norepinephrine biosynthesis. J. Biol. Chem. 239: 2910-2917.

Negishi, K., and B. D. Drujan (1978) Effects of catecholamines on the horizontal cell membrane potential in the fish retina. Sens. Processes 2: 388-395.

Otten, U., and H. Thoenen (1975) Circadian rhythm of tyrosine hydroxylase induction by short-term cold stress: Modulatory action of glucocorticoids in newborn and adult rats. Proc. Natl. Acad. Sci. U. S. A. 72: 1415-1419.

Rayborn, M. E., J. G. Hollyfield, P. V. Sarthy, and D. M. K. Lam (1981) The emergence, localization and maturation of neurotransmitter system during development of the retina in Xenopus laevis. II. Glycine. J. Comp. Neurol. 195: 585-594.

Redburn, D. A., Y. Clement-Cormier, and D. M. K. Lam (1980) GABA and dopamine receptor binding in retinal synaptosomal fractions. Neurochemistry 1: 167-182.

Roth, J. A., and C. N. Gillis (1975) Structural requirements for inhibitors of type $A$ and $B$ forms of rabbit monoamine oxidase by tricyclic psychoactive drugs. Mol. Pharmacol. 11: 28-35.

Sarthy, P. V., and D. M. K. Lam (1979) The uptake and release of $\left({ }^{3} \mathrm{H}\right)$ dopamine in the goldfish retina. J. Neurochem. 32 : 1269-1277.

Sarthy, P. V., M. E. Rayborn, J. G. Hollyfield, and D. M. K. Lam (1981) The emergence, localization and maturation of neurotransmitter system during development of the retina in Xenopus laevis. III. Dopamine. J. Comp. Neurol. 195: 595603.

Schorderet, M., and P. J. Magistretti (1980) The isolated retina of mammals: A useful preparation for enzymatic and/or binding studies of dopamine receptors. Neurochemistry 1: 337-354.

Stanton, H. C., G. Phinney, and R. L. Mueller (1974) Ontogenesis of choline acetyltransferase, tyrosine hydroxylase, monoamine oxidase and catechol- $O$-methyltransferase in the superior cervical ganglion of swine. Biochem. Pharmacol. 23: 3423-3430.

Tabor, C. W., H. Tabor, and S. M. Rosenthal (1954) Purification of amine oxidase from beef plasm. J. Biol. Chem. 208: 645661.

Thoenen, H. (1970) Induction of tyrosine hydroxylase in pe- 
ripheral and central adrenergic neurons by cold-exposure of rats. Nature 228: 861-862.

Thoenen, H. (1972) Neuronally mediated enzyme induction in adrenergic neurons and adrenal chromaffin cells. In Biochemical Society Symposium: Neurotransmitters and Metabolic Regulation, R. M. S. Smellie, ed., Vol. 36, pp. 3-15.

Thomas, T. N., Y. C. Clement-Cormier, and D. A. Redburn (1978) Uptake and release of $\left({ }^{3} \mathrm{H}\right)$ dopamine and dopaminesensitive adenylate cyclase in retinal synaptosomal fractions. Brain Res. 155: 391-396.
Watling, K. J., J. E. Dowling, and L. L. Iversen (1980) Dopaminergic mechanisms in the carp retina: Effects of dopamine, $\mathrm{K}^{+}$and light on cyclic AMP synthesis. Neurochemistry 1: 519-537.

Webster, H., and A. Ames, III (1969) Glutaraldehyde fixation of central nervous tissue: An electron microscopic evaluation in the isolated retina. Tissue Cell 1: 53-62.

Wurtman, R. J., and J. Axelrod (1963) A sensitive and specific assay for estimation of monoamine oxidase. Biochem. Pharmacol. 12: 1439-1441. 